\title{
Canine and feline cardiopulmonary parasitic nematodes in Europe: emerging and underestimated
}

\author{
Donato Traversa", Angela Di Cesare ${ }^{1 *}$ Gary Conboy ${ }^{2}$
}

\begin{abstract}
Cardiopulmonary nematodes of dogs and cats cause parasitic diseases of central relevance in current veterinary practice. In the recent past the distribution of canine and feline heartworms and lungworms has increased in various geographical areas, including Europe. This is true especially for the metastrongyloids Aelurostrongylus abstrusus, Angiostrongylus vasorum and Crenosoma vulpis, the filarioid Dirofilaria immitis and the trichuroid Eucoleus aerophilus (syn. Capillaria aerophila). The reasons of this emergence are little known but many drivers such as global warming, changes in vector epidemiology and movements in animal populations, may be taken into account. The purpose of this article is to review the knowledge of the most important heartworm and lungworm infections of dogs and cats in Europe. In particular recent advances in epidemiology, clinical and control are described and discussed.
\end{abstract}

\section{Background}

Nematodes affecting the cardiopulmonary system of dogs and cats have recently become the focus of increased attention from the scientific community due to their emergence in several European countries and the spread into previously non-endemic regions. This has been particularly the case for the metastrongyloids Aelurostrongylus abstrusus, Angiostrongylus vasorum and Crenosoma vulpis, the filarioid Dirofilaria immitis and the trichuroid Eucoleus aerophilus (syn. Capillaria aerophila). Indeed, the importance of infection with the heartworm (A. vasorum and D. immitis) and lungworm (A. abstrusus, C. vulpis and E. aerophilus) parasites in companion animals is heightened by the pathogenic potential of these nematodes, the challenges involved in diagnosis and (for some) their zoonotic potential.

The reasons for the apparent emergence of cardiopulmonary parasitoses in pets are unknown but several factors such as global warming, changes in vector seasonal population dynamics and movements in animal populations, may play a role in the recent rise in reports of infection in the various countries of Europe. Most of these parasites have an indirect life cycle, thus requiring

\footnotetext{
* Correspondence: dtraversa@unite.it
'Department of Comparative Biomedical Sciences, University of Teramo,

* Correspondence: dtraversa@unite.it
'Department of Comparative Biomedical Sciences, University of Teramo, Teramo, Italy
}

( 2010 Traversa et al; licensee BioMed Central Ltd. This is an Open Access article distributed under the terms of the Creative Commons Attribution License (http://creativecommons.org/licenses/by/2.0), which permits unrestricted use, distribution, and reproduction in any medium, provided the original work is properly cited. development. This is true for the gastropod-borne A. abstrusus, A. vasorum and C. vulpis and for the mosquito-transmitted D. immitis. Conversely, E. aerophilus may develop either directly in the environment or in earthworms acting as facultative intermediate hosts. Consequently, the likelihood for a dog or a cat becoming infected by a cardiopulmonary nematode depends not only on the presence of the vector(s) but also by their abundance and the prevalence of the infection. The occurrence of canine and feline heartworms and lungworms in different geographical areas is mainly influenced by the presence of competent gastropod and culicid species, with the exception of E. aerophilus, whose presence is guaranteed by the ubiquity of the earthworms and by the direct life cycle. Therefore, the interaction between the parasites, their hosts and the environment plays a central role in the apparent increase in exposure risk of these infections and is the basis for a new recognition of the relative importance of these parasites as aetiological agents in cardiopulmonary disease in companion animals. As a consequence, in the past few years several publications mainly related to distribution, epidemiology and control have appeared, although several aspects on biology, pathology and diagnostics still need to be elucidated. Therefore the present paper aims to review the current knowledge on 
cardiopulmonary nematodes of dogs and cats with a focus on their epidemiological patterns in Europe, on the pathogenic impact they have and on the new avenues and perspectives for diagnosis and control.

\section{Distribution in Europe: changing patterns, certainties and dilemmas}

The development and survival of the gastropod and insect vectors is mainly influenced by temperature, moisture and water availability, thus one of the most important factors currently favouring the dispersal and spread of vector-borne pathogens is global warming [1]. Specifically, given that rates of physiological processes in most invertebrates depend greatly on environmental temperature, the distribution and development rates of vector-borne diseases would be greatly influenced by a rise in temperature [2,3].

These environmental changes may play a causative role in the expansion of the geographic distribution of the heartworms, D. immitis ("canine heartworm") and A. vasorum ("French heartworm"). Population dynamics and activity of culicid and gastropod intermediate hosts are highly sensitive to temperature and moisture, and the development of nematode larvae in vectors is also known to be temperature-dependent [4]. Both D. immitis and $A$. vasorum have a huge range of competent vector species and their canine definitive hosts are distributed worldwide. As a likely consequence of these factors, the most recent papers report a trend in the geographic spread of both of the heartworms, $D$. immitis and $A$. vasorum, into previously free areas [5-9]. Transmission of $D$. immitis by mosquitoes is strictly dependant on a suitable climate allowing the larval development in the vectors, thus environmental temperatures are the main factors favoring the life cycle of this parasite $[5,10,11]$. Some climate-based models have been developed to investigate the possible changes that may occur in terms of distribution and seasonality for $D$. immitis in response to global warming $[5,12,13]$. These studies clearly demonstrated that Dirofilaria infections in Europe have seasonal transmission patterns with peak activities in the summer months and that warm climates facilitate larval development in the intermediate hosts. Therefore, changes in climate are likely to have a strong impact on parasite distribution, development and transmission patterns. The current trend of increasing temperatures will probably allow the spread of the nematode in several countries [5]. With regard to A. vasorum, there is clear evidence of both an increase in the number of cases reported within known endemic foci (e.g. France, Denmark and UK) and the appearance of new foci in several regions previously free of infection $[6,9,14,15]$. There is great interest in understanding the reasons for the spread of French heartworm and to elucidate the factors, global warming or other(s), that may be involved. The major hindrance for such studies on A. vasorum is the lack of detailed information on key biological features of the nematode, e.g. influence of climatic factors on development and transmission in the vectors and the role of the vector species themselves. This information is necessary before computer modelling studies, similar to those used for $D$. immitis, can be utilized. Preliminary work has been carried out using a climatic envelope to address at least the geographic regions at risk of spread and/or invasion by $A$. vasorum [7]. Even though it is based on incomplete data, this climate-matching model showed that there are several European regions, e.g. central-northern areas of Europe and Italy, which offer suitable ecological and epidemiological conditions for the expansion of current endemic foci of $A$. vasorum and the establishment of further new endemic foci. These considerations seem to be supported by the events as reported in Italy. In this country A. vasorum infection was first reported over twenty years ago in red foxes $[16,17]$ and for quite some time infection was likely confined to this host until recently, when angiostrongylosis has been reported with increasing frequency in dogs [18-20]. Growing awareness among clinicians and researchers may have played a role in the increase in angiostrongylosis diagnoses in dogs, but the trend in higher incidence observed in other European countries and the concomitant expansion in foxes strongly indicate that the parasite is actually emerging $[7,9]$. Although lack of awareness and misdiagnosis could have resulted in an underestimation of infection levels in dogs, the high level of pathogenicity associated with $A$. vasorum infection makes it unlikely that clinical cases in previous years were missed. Nonetheless, more studies are necessary to elucidate the potential effects of climatic variables on parasite and intermediate host development rates as well as the transmission patterns in both endemic and non-endemic areas, and to address the question whether global warming and/or other factors actually explain the current spread of A. vasorum.

Prediction studies are warranted for two other gastropod-borne lungworms, for which no extensive computer modelling or epidemiological research data are available, i.e. A. abstrusus ("feline lungworm") and C. vulpis ("fox lungworm"). Recent reports have indicated a possible expansion in the geographical range of $A$. abstrusus infection and/or a new awareness that infection in cats may be much more common than previously thought $[20,21]$. In particular there are endemic areas in Europe, like Portugal [22] and Italy [23,24], where the prevalence of this lungworm is $\sim 20 \%$ and aelurostrongylosis is a significant cause of feline respiratory disease. The fox lungworm, C. vulpis, affects wild and domestic canids in Europe and North America and, though neglected in the 
past, has recently been detected and/or recognized as a cause of canine respiratory disease in different countries of the Old Continent, e.g. Switzerland, Portugal, Germany [25-27]. Whether the apparent emergence of $A$. abstrusus and C. vulpis reflects an increased infection exposure risk or the utilization of better diagnostic methods is unclear. Unlike canine angiostrongylosis, infection of $A$. abstrusus in cats and C. vulpis in dogs tends to be insidious even in cases involving clinical disease. Fatal infection of $A$. abstrusus in cats is relatively uncommon and fatal C. vulpis infection has never been reported in dogs. Clinicians failing to consider C. vulpis infection in cases of dogs suffering signs of chronic cough are most likely to misdiagnose and treat the condition as allergic respiratory disease. Since treatment of allergic respiratory disease is symptomatic, the lungworm infected dog will show clinical improvement and therefore the clinician will have no reason to suspect that they have made a misdiagnosis. The same may be true of cats infected with $A$. abstrusus. Nonetheless, for gastropod-transmitted parasitoses, the geographic spread of slugs and snails driven by conditions of global warming may play a role in the incidence and distribution of these parasites [28-31]. With similar life cycle patterns, the same factors involved in the spread of $A$. vasorum would likely also have an affect on A. abstrusus and C. vulpis. This remains speculative awaiting further study.

Canine and feline respiratory infection by E. aerophilus is considered sporadic and most often sub-clinical. However, in the past decade, clinical cases in animals have been reported [32-35] as well as zoonotic infection in humans [36]. In Europe, the nematode is commonly found in wildlife, but recently it has been identified in companion animals, for instance in both dogs and cats from Italy $[20,37]$ and in dogs in Portugal [26]. Knowledge of epidemiological data (e.g. range of hosts and geographic distribution) of E. aerophilus in Europe is fragmentary, thus at the moment it is difficult to assess to what degree this parasite may be spreading or what influence global warming or other factors may have on the current distribution.

Indeed, although climate changes seem to play a key role into the epidemiological variations for pet heartworms and lungworms, other possible factors can not be ruled out. Among them, animal travel, international trade, lack of large-scale surveillance and control programs and, possibly, enhanced awareness of veterinarians and improved diagnostic tools may also play a role $[21,38,39]$. Thus there is significant risk of introduction of these parasites through the movement of infected animals to previously non-endemic areas as seen with $A$. vasorum [40,41] and Dirofilaria spp. [42,43]. In addition, the introduction of competent vectors through commercial trade goods may favour the establishment and
Table 1 Examples of prevalence rates/ranges (\%) or single report/s (S) for Aelurostrongylus abstrusus (Aa), Crenosoma vulpis (Cv) and Eucoleus aerophilus (Ea) in some European countries

\begin{tabular}{llll}
\hline Country & $\mathbf{A a} \%$ & $\mathbf{C v} \%$ & $\mathbf{E a} \%$ \\
\hline Italy & 24.4 & $\mathrm{~S}$ & $2.8(\mathrm{D})-5.5(\mathrm{C})$ \\
France & $\mathrm{S}$ & - & - \\
Switzerland & $\mathrm{S}$ & $\mathrm{S}$ & - \\
Spain & 1 & - & $1.3(\mathrm{C})^{*}$ \\
Portugal & 17.4 & - & $0.3(\mathrm{D})$ \\
Great Britain & $\mathrm{S}$ & $\mathrm{S}$ & - \\
Denmark & $\mathrm{S}$ & 1.4 & - \\
Holland & 2.6 & - & - \\
Ireland & $\mathrm{S}$ & $\mathrm{S}$ & - \\
Germany & $0.7-6.5$ & $0.9-6$ & $0.2(\mathrm{C}, \mathrm{D})^{*}$ \\
Belgium & $\mathrm{S}$ & - & - \\
Norway & $\mathrm{S}$ & - & - \\
Poland & $\mathrm{S}$ & - & - \\
Hungary & $\mathrm{S}$ & - & - \\
Croatia & $0.38-22$ & - & - \\
Greece & $\mathrm{S}$ & - & - \\
Romania & 5.6 & - & $3.1(\mathrm{C})$ \\
Turkey & $\mathrm{S}$ & - & - \\
\hline
\end{tabular}

C:cats; D:dogs; *The nematode was identified as Capillaria spp.

Table 2 Examples of prevalence rates/ranges (\%) or single report/s (S) for Angiostrongylus vasorum (Av) and Dirofilaria immitis $(D i)$ in some European countries

\begin{tabular}{lll}
\hline Country & Av\% & Di\% \\
\hline Italy & $\mathrm{S}$ & $0.6-80 ; \mathrm{S}(\mathrm{C})$ \\
France & $\mathrm{S}$ & $0.6-6.8$ \\
Switzerland & $\mathrm{S}$ & 1.6 \\
Spain & $\mathrm{S}$ & $0.6-58.8$ \\
Portugal & - & $\mathrm{S}$ \\
Great Britain & $\mathrm{S}$ & $\mathrm{S}$ \\
Irland & $\mathrm{S}$ & - \\
Denmark & 2.2 & - \\
Netherland & 0.8 & - \\
Sweden & $\mathrm{S}$ & - \\
Germany & $0.3-7.4$ & - \\
Czech Republic & - & $\mathrm{S}$ \\
Slovakia & - & $\mathrm{S}$ \\
Hungary & - & $\mathrm{S}$ \\
Croatia & - & $\mathrm{S}$ \\
Serbia & - & 6.2 \\
Romania & - & $\mathrm{S}$ \\
Bulgaria & - & $\mathrm{S}$ \\
Albania & - & $\mathrm{S}$ \\
Greece & 1.1 & $10-34$ \\
Turkey & - & $\mathrm{S}$ \\
\hline C:ats; D:dogs. & &
\end{tabular}

C:cats; D:dogs. 


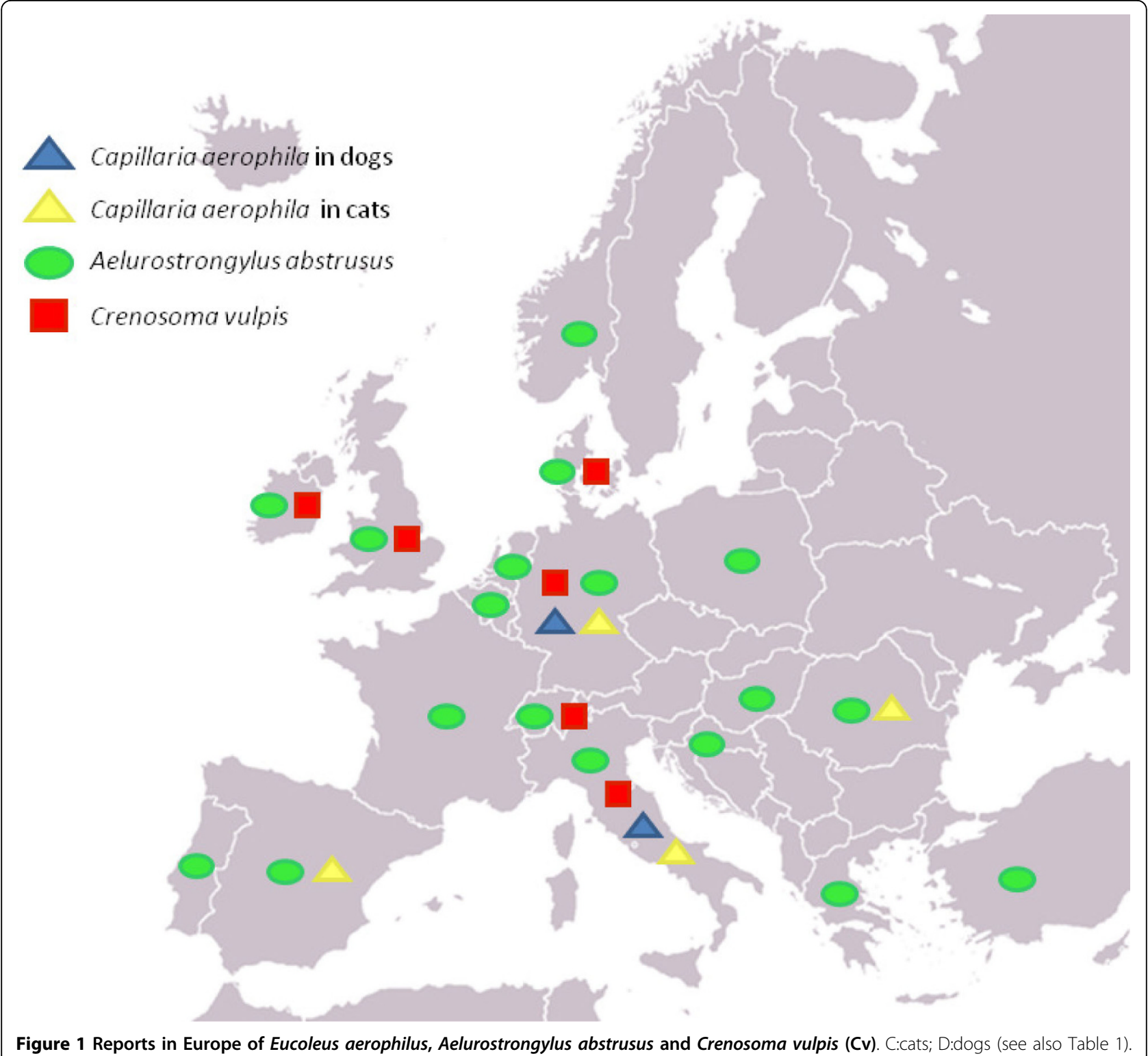

spread of parasites to new regions, as already discussed for Aedes albopictus and Dirofilaria spp. [44,45].

Tables 1 and 2 report the prevalence rate or single description/s of cardio-pulmonary nematodes in Europe, while Figures 1 and 2 depict the distribution of lungworms (C. vulpis, A. abstrusus and E. aerophilus) and heartworms (i.e. D. immitis and A. vasorum).

The information reported in Tables 1 and 2 and Figures 1 and 2 are based on refs [14,15,18-27,37,46-89].

\section{Pathological significance}

Clinical aspects of canine and feline heartworm and lungworm infections have been extensively reported and interested readers are referred to various reviews [9,21,90-94]. Therefore, this chapter is intended to summarize the main aspects of the pathogenic role of cardiopulmonary nematodes in clinical settings and to emphasize their potential role as a zoonotic threat.

These infections present varying clinical outcomes depending on different variables such as worm burden, age and immune response of the infected animal, and concomitant diseases. Given the similar localization of adult stages (i.e. right side of the heart and the pulmonary arteries), angiostrongylosis and cardiopulmonary filariosis may present similar clinical pictures. Infection in dogs with either parasite can result in cardiac damage progressing to right-sided congestive heart failure and signs of exercise intolerance, ascites, tachycardia, severe dyspnoea and syncope. Respiratory signs such as cough, dyspnoea and tachypnoea can also occur with either 


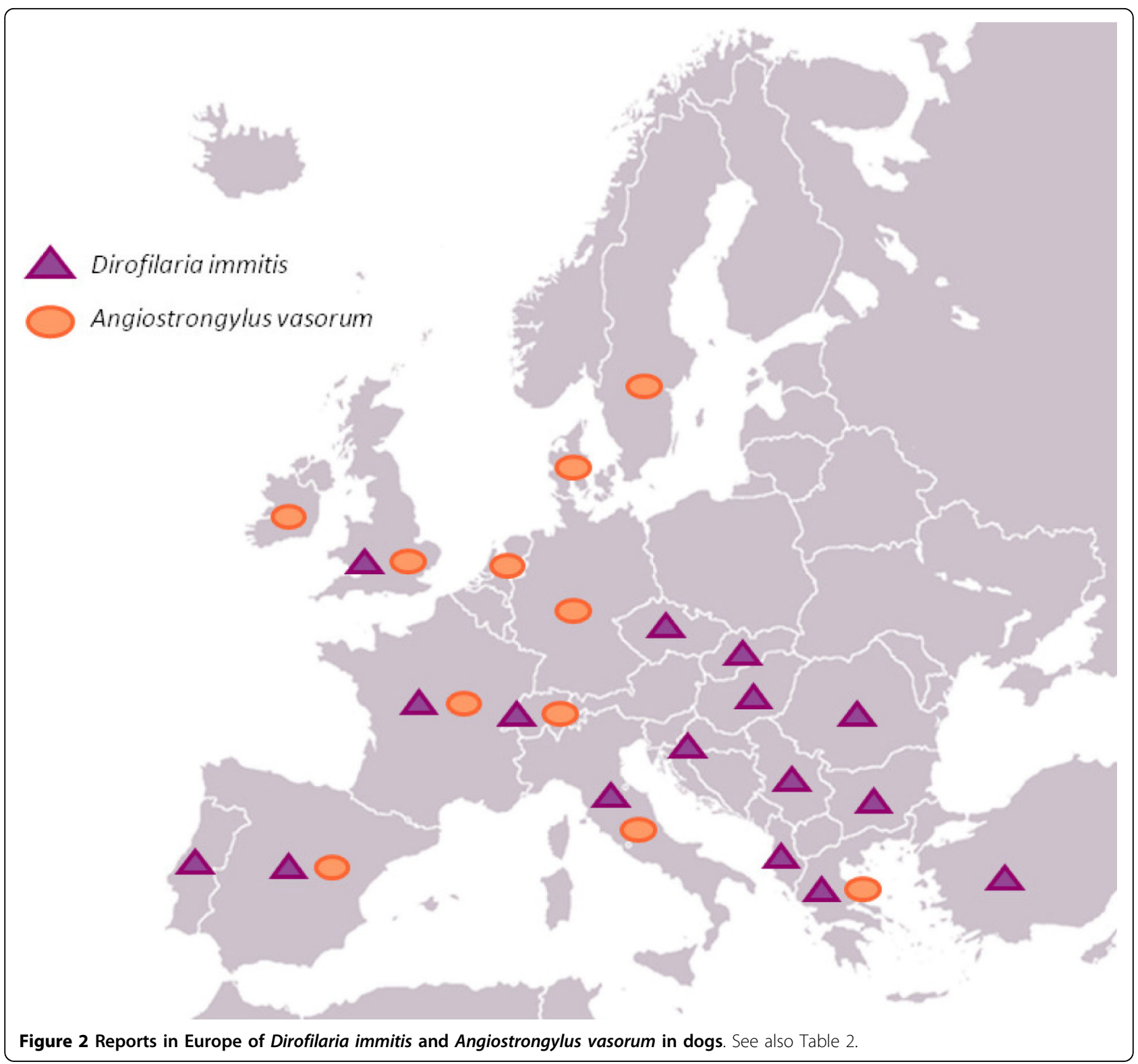

heartworm. Cardiopulmonary filariosis in cats can involve a prolonged asymptomatic prodromal period ending with the sudden death of the animal. A distinctive clinical sign for $A$. vasorum infection is the presence of bleeding disorders and coagulopathies, likely due to disseminated intravascular coagulation $[9,94,95]$. Such a disorder triggers a wide range of symptoms which may have serious consequences [94], for instance neurological signs due to bleeding into the brain or spinal cord [96] or massive bleeding in body cavities [19].

Symptoms in cats infected by $A$. abstrusus are not always detectable, as the disease may be asymptomatic or subclinical [97-99]. The mild forms, which are frequent in adult animals and/or in the case of low worm burdens, may be self-limiting and respiratory symptoms gradually and spontaneously disappear within weeks [98]. When present, the clinical signs are due to the inflammatory response caused by the eggs shed by the adult females and the migration of the first stage larvae (L1) up the bronchial tree causing lesions in the pulmonary alveoli, bronchioles and local arteries [100]. Respiratory signs, e.g. mild to intense cough, sneezing, mucopurulent nasal discharge, dyspnoea, open-mouthed abdominal breathing, and even death, are most often observed in young, debilitated and/or immunosuppressed animals [48,101-103].

Similar clinical signs are present in animals infected by E. aerophilus (cats and dogs) and C. vulpis (dogs). In 
general, pulmonary capillariosis is typically characterized by a chronic bronchitis and infected animals may present with minimal respiratory signs (e.g. bronchovesicular sounds) to inflammation, sneezing, wheezing, and chronic dry cough. When bacterial complications intervene, cough may become moist and productive and bronchopneumonia and respiratory failure occur. Heavy parasite burdens may lead to mortality [35,104-106]. Canine crenosomosis is usually characterized by bronchitis with a dry, non-productive cough that can be elicited by tracheal palpation and may be accompanied by gagging $[107,108]$. High parasitic burdens may, in turn, induce mucoid or mucopurulent discharge in the airways and the cough is chronic and productive. Although cough may be severe, fatal infections in dogs have never been reported [93]. In most cases, mild to moderate bronchial patterns that may have a diffuse interstitial component most evident in the diaphragmatic lobes are observed on radiographs [25,62,107-112].

While the metastrongyloid infections are restricted to their animal hosts, D. immitis and E. aerophilus also have zoonotic potential. Indeed, pulmonary capillariosis in humans is an occasional event, with about a dozen cases described to date in the scientific literature from Asia, Africa and Europe [36,113-115]. Human infection is characterized by bronchitis, coughing, mucoid sputum, presence of blood in the mucous, fever, and dyspnoea. The last described report was a cryptic case of infection in a woman from Serbia that resembled a bronchial carcinoma [36]. The infected patient had a productive cough with purulent expectorates and the computed tomography scan revealed bronchopneumonic shadows, and spotted, partially confluent, nodular, and banding infiltrative lesions of the pulmonary parenchyma, similar to those occurring in lung cancers. More in depth analysis revealed the presence of E. aerophilus eggs in the bronchial biopsy, thus suggesting that the parasites likely died in the bronchial tree, causing abscesses which appeared as tumor-like lesions. As illustrated by this case, the diagnosis of human capillariosis may be a serious challenge due to the likelihood of infection being mistaken for cancer [36]. Although the subcutaneous dwelling Dirofilaria repens is the most common filarial zoonotic pathogen in Europe, the possibility that human infections by $D$. immitis may occur should be taken into serious account. Human infection with $D$. immitis has been mostly reported from USA and Far East especially where the parasite is endemic in the dog population $[92,116]$. Nonetheless, due to the frequency of subclinical infections and the lack of specific diagnostic tests, the actual incidence and prevalence of human cases is likely underestimated worldwide $[116,117]$ and this could be also true for European regions where the infection is endemic (e.g. North of
Italy). In general, after the bite of an infected mosquito, the vast majority of larvae are eliminated in the human host by the immune system [118]. When some larvae continue their migration, thus reaching the pulmonary arteries and their branches, they elicit a local inflammatory response which can kill the larvae [117]. Thereby, the worms are incorporated into granulomas, appearing as typical 'coin'-like densities on radiographic examination. The majority of these infections are asymptomatic but in some cases infected people may present with pneumonitis-like symptoms $[117,119-121]$. As is the case with $E$. aerophilus, cardiopulmonary specialists may be faced with significant diagnostic challenges, given the lack of adequate diagnostic tests and the number of other disease conditions (e.g. fungal, bacterial and neoplastic diseases) which can result in similar pulmonary lesions. In addition, infection involving extra-pulmonary tissues have also been observed, e.g. in a branch of the left testicular artery, within a hepatic nodule in the peritoneal cavity and the eye $[116,117,122]$.

Even though most of the past cases of human infection in Europe have been found to be caused by $D$. repens, further studies are warranted to elucidate the current rate of human infections by $D$. immitis in the Old Continent. This is particularly true considering the increasing distribution of the parasite in different geographical areas of Europe and the spreading of new competent vectors, which indeed pose a present and future public hazard [5].

\section{Are heartworms and lungworms an actual diagnostic challenge for parasitologists and practitioners?}

Cardiopulmonary parasitoses in dogs and cats cannot be easily diagnosed clinically, because several other conditions should be considered in the differential diagnoses as well as sub-clinical or atypical infections that may occur. Infections caused by $A$. vasorum and $D$. immitis are characterized by a wide spectrum of clinical features, ranging from a subclinical or mild disease to a severe, potentially fatal manifestation. Parasitoses caused by $A$. abstrusus, C. vulpis and E. aerophilus are also difficult to interpret in current clinical practice since the signs of disease are similar or the same as those associated with a series of other respiratory conditions. In general, clinical signs such as fatigue, cough, sneezing, wheezing, mucopurulent nasal discharge, dyspnoea, open-mouthed abdominal breathing and bronchopneumonia, oblige veterinarians to include a multiplicity of diseases and distresses in the differential diagnosis, e.g. viral, bacterial and fungal diseases, non-infective inflammatory (e.g. nasopharyngeal polyps and allergic bronchitis) disorders, foreign bodies and respiratory neoplasms $[21,33,34,123]$. Additionally, these infections often present nonspecific 
abnormal radiographic and haematological findings, thus proper diagnostic methods are critical to achieve a timely and reliable diagnosis for cardiopulmonary nematodes affecting cats and dogs [9,21,33,34,123-125].

The accurate and definitive diagnosis of lungworm infections is achieved by the identification of parasitic biological stage(s) in a series of samples. For nematodes whose eggs hatch in the bronchial tree of the infected animals, i.e. A. vasorum, C. vulpis and A. abstrusus, $\mathrm{L} 1 \mathrm{~s}$ are the "target" to be identified in the faeces by using copromicroscopic techniques such as direct smears, faecal flotation and Baermann examinations. Direct smears are inexpensive and easy to perform but have poor sensitivity due inadequate sample size and will only detect infections in animals that are shedding large numbers of larvae in the faeces $[21,126]$. Faecal flotation examinations also lack detection sensitivity due to issues of sample size and the damaging effects of the flotation media on the larvae (Figure 3). In fact, high specific gravity concentrated salt or sugar solutions tend to induce larval osmotic damage due to dehydration. Larvae may be completely damaged and therefore undetectable or suffer a loss of morphologic detail rendering accurate larval identification difficult to impossible, especially for inexperienced diagnosticians [21]. Zinc sulphate (specific gravity $=1.18-1.2$ ) appears to be the most reliable media for use in the detection of L1 $\mathrm{s}$ on fecal flotation but still may miss $40-90 \%$ of the positive animals [127]. The Baermann faecal examination method remains the gold standard for the diagnosis of the infections caused by $A$. vasorum, $C$. vulpis and $A$. abstrusus, due to the positive hydro-/thermo-tropism exhibited by live L1 $[21,93]$. When the larvae are present in the stool samples, a thorough morphometric and morphological examination is required for an accurate identification of L1. Lungworm larvae should be differentiated from i) each other, ii) those of other less common parasites, iii) hookworm larvae that may be present in samples that have been allowed to incubate and iv) free-living or plant parasitic nematodes that may be present in samples collected from the ground. In addition to A. abstrusus (Figure 4), another less common parasitic larvae that may be detected using the Baermann technique in feline fecal samples includes the lungworm Oslerus rostratus. In canine samples, larvae of the lungworms Filaroides spp. and Oslerus osleri as well as those of the intestinal parasite Strongyloides stercoralis (Figure 5) may also be detected and need to be differentiated from $A$. vasorum (Figure 6) and C. vulpis (Figure 7) [93]. The finding of L1 s of Filaroides spp. and Oslerus spp. in samples examined using the Baermann method is unlikely because larvae of these nematodes are lethargic and therefore do not migrate out of the faeces. Although false negative results commonly occur, detection of

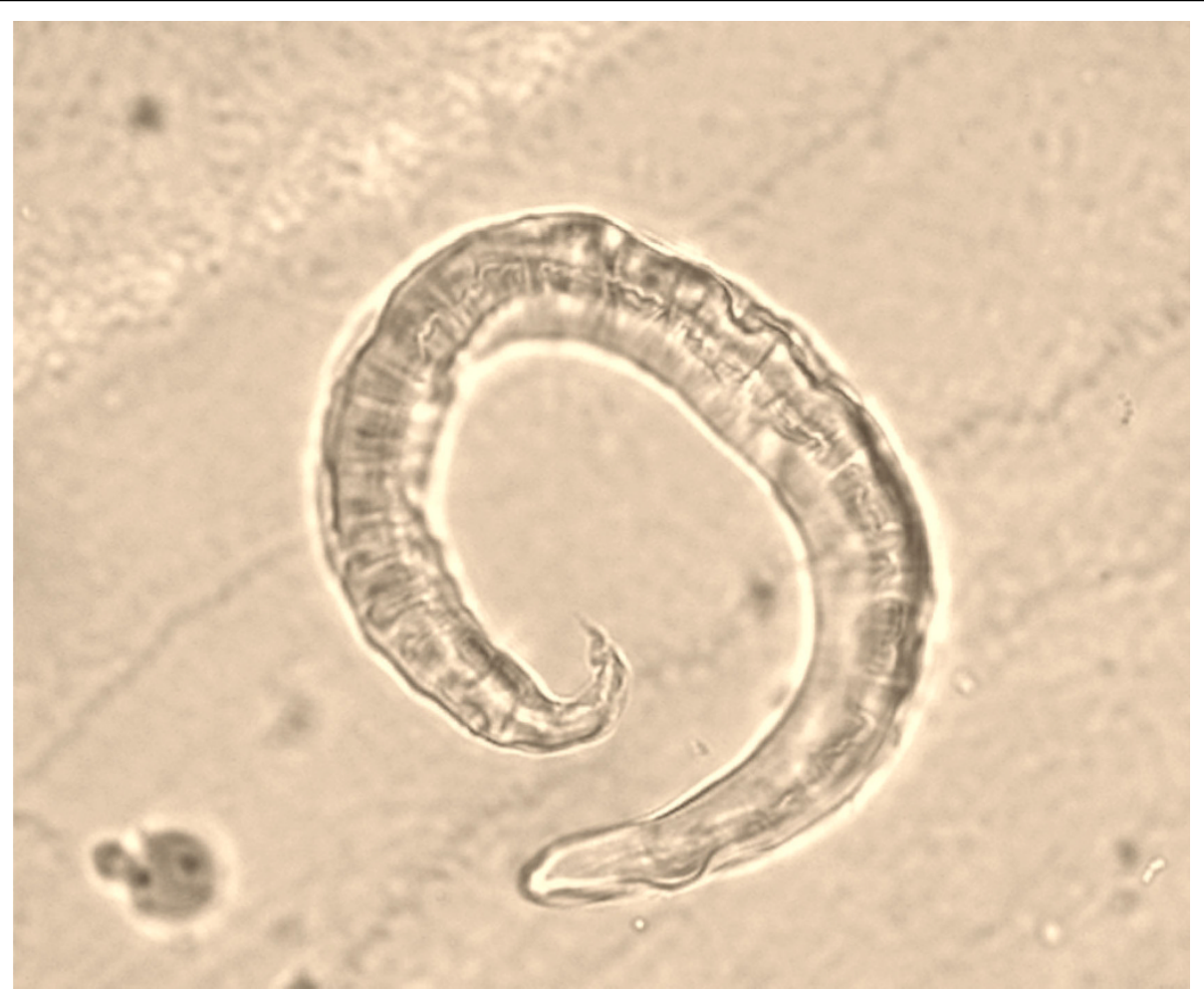

Figure 3 Floatation with Zinc Sulphate: Angiostrongylus vasorum, dehydrated first stage larva. 


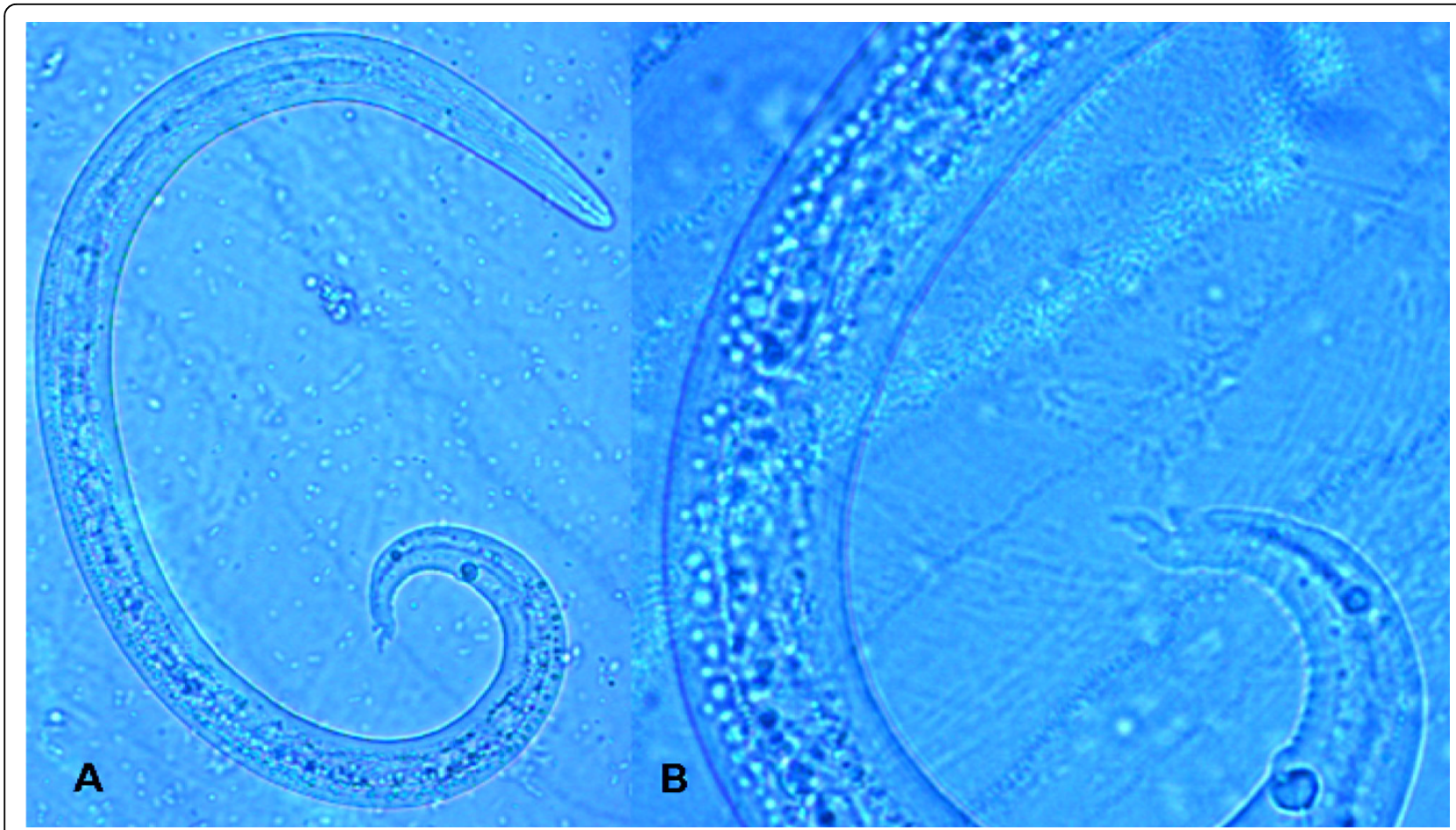

Figure 4 Baermann test: Aelurostrongylus abstrusus, first stage larva (A) and magnification (B) of the S-shaped caudal end with the typical dorsal spine.

these larvae in faeces is more reliably accomplished through centrifugal faecal flotation using zinc sulfate solution (specific gravity $=1.2$ ) than with the Baermann technique. Table 3 details the key morphometric and morphological characters (i.e. length, width, esophageal and tail morphology) to be evaluated when nematode larvae are found in canine or feline faeces. The presence of nematode contaminants in the faeces greatly complicates the evaluation of the sample. Due to the large number of species of free-living/plant parasitic nematodes involved, there is no single morphological character that allows the diagnostician to differentiate the contaminants from the parasitic L1. A diagnostician should suspect the possibility of contaminants if the sample contains adult stages (i.e. males with spicules, females with vaginal opening and uterus containing eggs) or the size measurements of the nematodes recovered are inconsistent with the range expected for parasitic L1 (i.e. 150 - 412 microns). Since S. stercoralis may develop a free-living generation if the faecal sample is allowed to incubate, even the presence of adult stages does not definitively indicate contamination has occurred. When contamination has been suspected, specific instructions should be given to the animal's owner on proper sample collection (faeces should be collected immediately after deposit on the ground) and the animal should be re-tested.
Although the Baermann examination is the gold standard for diagnosing angiostrongylosis, aelurostrongylosis and crenosomosis, this method has inherent limitations. It is relatively time-consuming (i.e. 12-48 hrs) and false negative results can occur due to prepatent infections and the intermittent fecal larval shedding pattern typical of metastrongyloids. Thus, repeated examinations (e.g. samples collected for three consecutive days) are necessary to increase the sensitivity $[21,93]$.

Molecular studies have overcome the inherent limitation of conventional methods for the diagnosis of aelurostrongylosis and angiostrongylosis. The DNA of the feline lungworm is detectable by a nested PCR based on genetic markers within the ribosomal DNA. This DNAbased assay may be applied to both faecal and pharyngeal swab samples with a specificity and sensitivity of about $100 \%$ and $97 \%$ respectively, which are values much higher than those that the classical methods may achieve [128]. Very recently, innovative techniques have been assessed for the French heartworm as well. A realtime PCR specific for A. vasorum ribosomal regions was developed to amplify parasite DNA from both definitive and intermediate host samples. For clinical purposes, this assay was able to detect a single L1 in $200 \mu \mathrm{l}$ of blood and in $200 \mathrm{mg}$ of faeces. This method showed a more efficient means for the diagnosis of canine angiostrongylosis with a lower limit of detection than the 


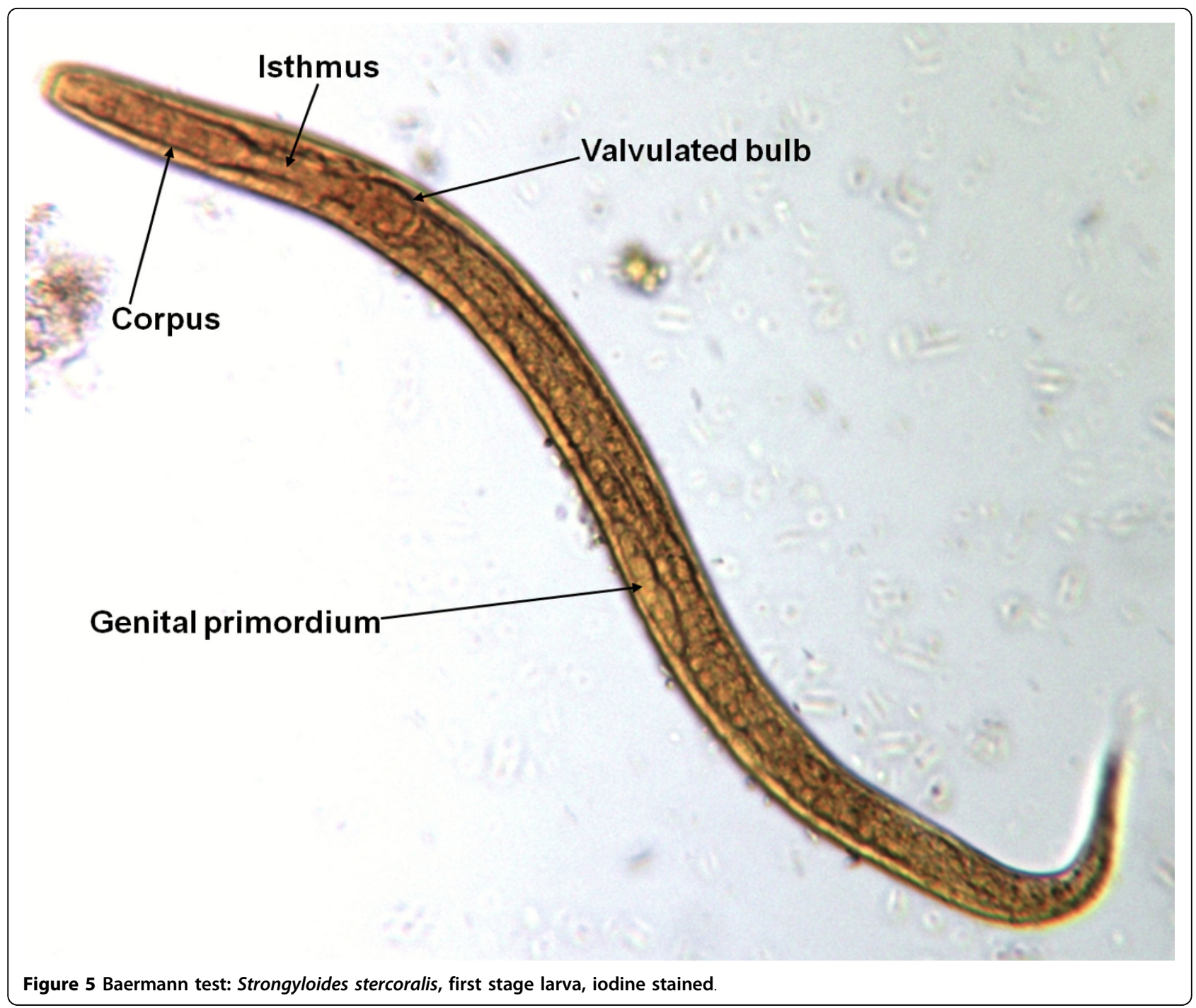

Baermann method [129]. Additionally, circulating adult worm antigen has been detected in the serum of $A$. vasorum infected dogs through the use of a sandwichELISA. A sensitivity of $92 \%$ and a specificity of $100 \%$ were reported for the sandwich-ELISA [130]. Detection of circulating adult worm antigen has great promise as a method for the diagnosis of angiostrongylosis in dogs.

Canine and feline capillariosis is diagnosed by the detection through standard fecal flotation of the typical trichuroid eggs passed in the faeces by the infected hosts. The eggs of E. aerophilus (Figure 8A) need to be differentiated (Table 4) from the eggs of intestinal whipworm Trichuris spp. (Figure 8B), the nasal capillarid Eucoleus boehmi (Figure 9A) and those of the stomach capillarid Aonchotheca putorii. Indeed, the similarity in morphological features of Eucoleus and Trichuris eggs make accurate identification a challenge for microscopists. The possibility of misdiagnosis and the practice of identifying eggs only as "capillarid" or "trichuroid" have likely complicated the interpretation of field survey data with respect to prevalence of infection for the various capillarids [37,93], which is likely in mixed infections (Figure 8). When the barrel-shaped eggs are found in samples following copromicroscopic analysis with flotation solutions (specific gravity $=1.2-1.35$ ) their shell wall surface pattern (Figure 9B, Table 4), size and plug morphology must be carefully examined (Table 4) to achieve a reliable diagnostic result. At the moment, no molecular methods have been developed for the diagnosis of the infections caused by E. aerophilus and C. vulpis, although genetic investigations are presently ongoing to characterize ribosomal and mitochondrial diagnostic markers (Traversa et al., unpublished).

In contrast to most of the other cardiopulmonary nematodes, blood is the biological sample to examine for the diagnosis of heartworm infection. Adult female 


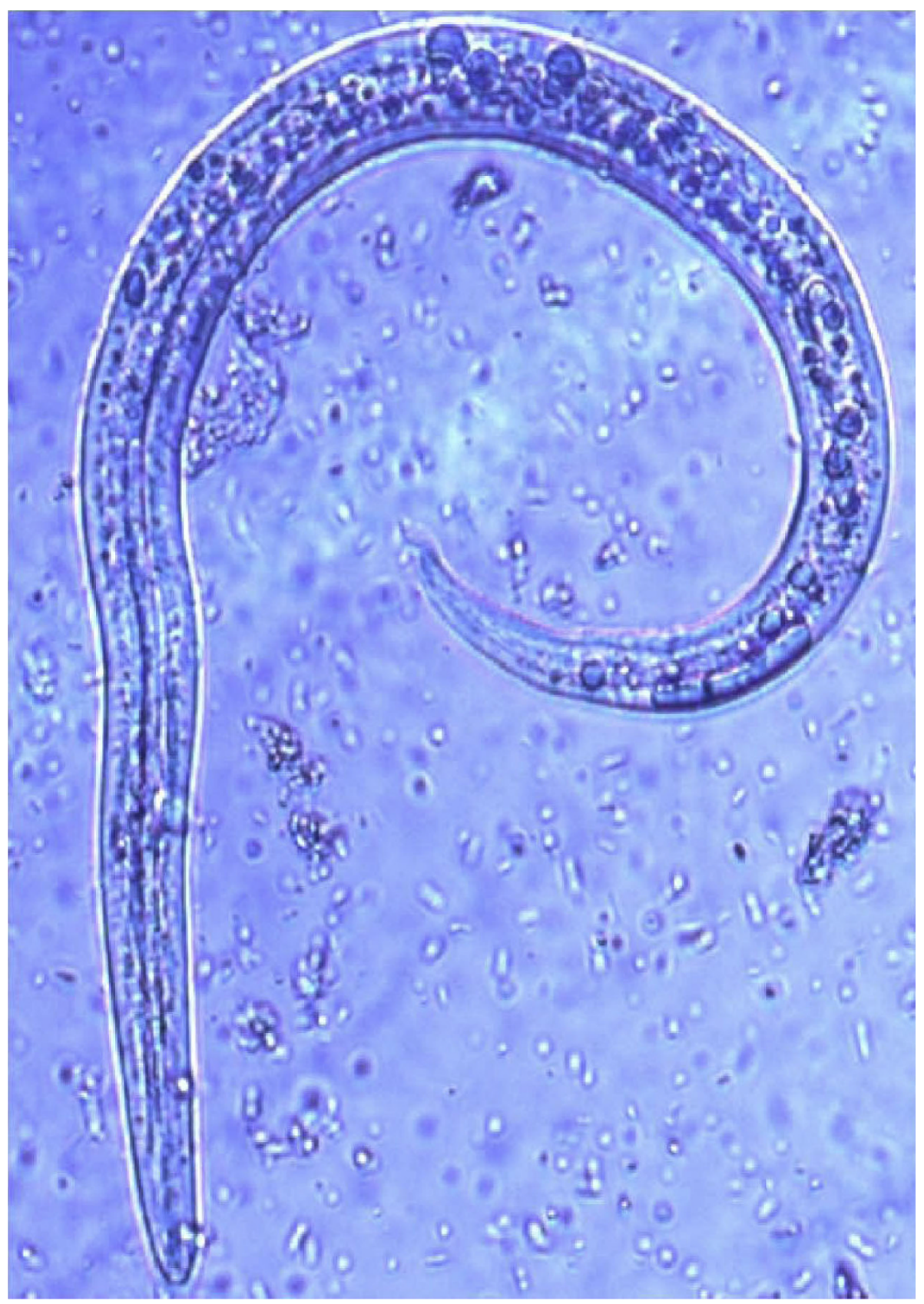

Figure 6 Baermann test: Angiostrongylus vasorum, first stage larva.

Dirofilaria produce live microfilariae (i.e. L1s) that can be detected in the bloodstream of infected animals by several microscopic techniques, e.g. the Knott's method [92]. Microfilariae of D. immitis (Figure 10) must be differentiated $[106,131]$ from those of other (non cardiopulmonary) filarioids infecting dogs and cats including D. repens and Acanthocheilonema (= Dipetalonema) reconditum based on differences in morphology and size measurements (Figures 11, 12, Table 5). Anterior-end morphology of $D$. immitis (gently tapered) differs from that of $A$. reconditum and $D$. repens (blunt). An artifact of fixation in $2 \%$ formalin in the Knott's method can cause a distinctive curve in the tail of $A$. reconditum (ie "button-hook" tail) and D. repens while the tail of $D$. immitis remains straight. However, the occurrence of the tail artifact is highly variable and therefore, $A$. reconditum and $D$. repens cannot be ruled out as possibilities in microfilaria with a straight tail. There are definite 


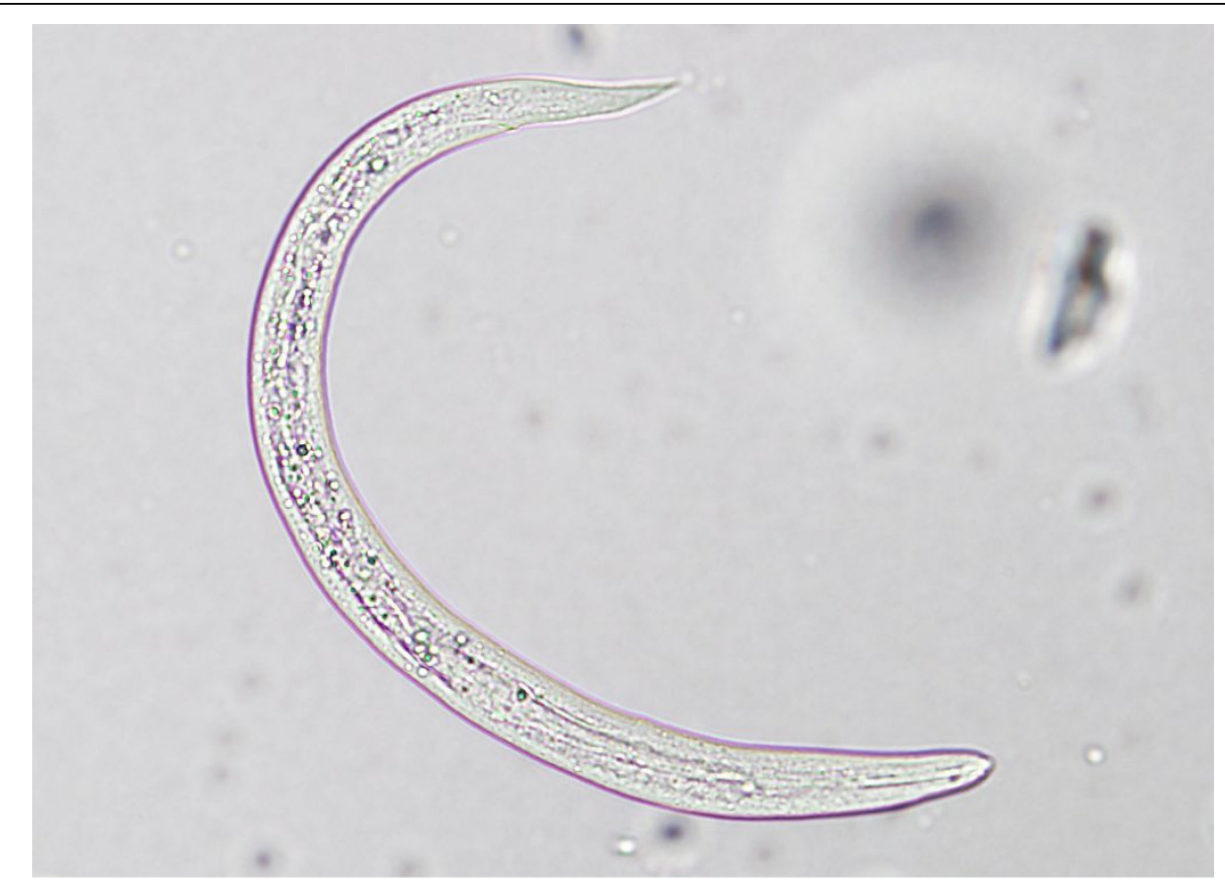

Figure 7 Baermann test: Crenosoma vulpis, first stage larva.

differences in size between the microfilaria of these three species (see Table 5) that can be used to accurately identify the parasite involved.

Microfilaria detection tests lack sensitivity in that up to $20-30 \%$ of $D$. immitis infected dogs are not microfilaremic due to single-sex infections, low worm burdens, immune reactions or past administration of parasiticides with microfilaricidal activity [92]. A much more reliable method for diagnosis of $D$. immitis infection in dogs is through the use of commercial kits for the detection of circulating adult female antigen in the blood. Nonetheless, there is a small proportion of microfilariemic animals which may have negative results using the antigen detection tests, due to such reasons as low worm burden or possible persistence of microfilariae after the death of adult worms $[87,92]$.

Table 3 Cardiopulmonary nematodes affecting dogs and cats: differential features of first stage larvae found in faecal samples

\begin{tabular}{|c|c|c|c|c|}
\hline Nematode & $\begin{array}{l}\text { Length } \\
(\mu \mathrm{m})\end{array}$ & Oesophagus & Caudal end & Refs \\
\hline $\begin{array}{l}\text { Aelurostrongylus } \\
\text { abstrusus }\end{array}$ & $300-390$ & Non-rhabditiform; $1 / 3-1 / 2$ the length of the larvae & Notched and S-shaped & {$[97,131]$} \\
\hline $\begin{array}{l}\text { Angiostrongylus } \\
\text { vasorum }\end{array}$ & $310-400$ & Non-rhabditiform; $1 / 3-1 / 2$ the length of the larvae & Tip with a dorsal spine and a sinus wave curve & {$[21,93]$} \\
\hline Oslerus rostratus & $335-412$ & Non-rhabditiform; $1 / 3-1 / 2$ the length of the larvae & $\begin{array}{l}\text { Constriction anterior to the end; tip with a } \\
\text { kinked appearance }\end{array}$ & {$[21,93]$} \\
\hline $\begin{array}{l}\text { Oslerus osleri } \\
\text { Filaroides spp. }\end{array}$ & $\sim 250$ & Non-rhabditiform; $1 / 3-1 / 2$ the length of the larvae & $\begin{array}{l}\text { Absence of dorsal spines and S-shaped end } \\
\text { with a slight kink }\end{array}$ & {$[91,93]$} \\
\hline Crenosoma vulpis & $240-310$ & Non-rhabditiform; $1 / 3-1 / 2$ the length of the larvae & Pointed and straight tail & {$[127]$} \\
\hline $\begin{array}{l}\text { Strongyloides } \\
\text { stercoralis }\end{array}$ & $150-390$ & $\begin{array}{l}\text { Rhabditiform (corpus, isthmus, valvulated bulb); } 1 / 4 \text { the } \\
\text { length of the larvae }\end{array}$ & Pointed and straight tail & {$[93]$} \\
\hline Hookworm larvae & $290-360$ & & & \\
\hline
\end{tabular}




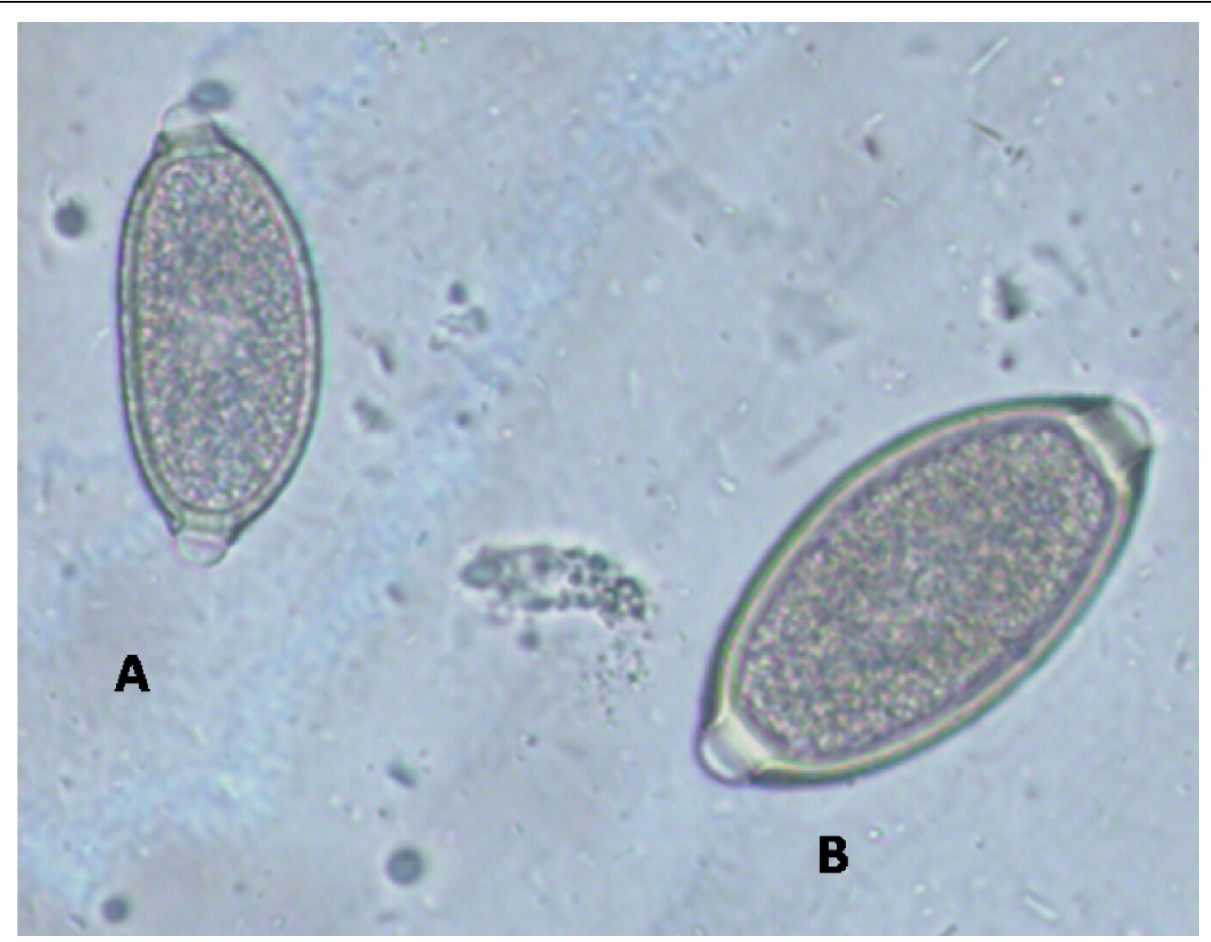

Figure 8 Floatation with Zinc Sulphate: eggs of Eucoleus aerophilus (A) and Trichuris vulpis (B)

It is also worthy of note that the detection of circulating larvae in cats is infrequent due to low and/or short-lasting periods of microfilaremia and non-patent infections [92]. In cats the D. immitis antigen detection kits may detect infections caused by a low number of female adults but in these animals, these assays have inherent limitations due to the great possibility of male worm only infections, which can be fatal even in the presence of a single nematode. In general in cats a negative result using antigen detection kits can not rule out the possibility that animals are infected with only male worms, a single female filaria, non-mature worms or old adult worms [92].

To overcome the limits of classical methodologies, several recent studies have been undertaken to differentiate between the various filarioid parasites of pets irrespective of their life cycle stage through the use of molecular techniques. Indeed, D. immitis, D. repens and $A$. reconditum may be differentiated using interspecific variability in their ribosomal or mitochondrial DNA by

Table 4 Capillariid and trichuroid nematodes affecting dogs and cats: differential features of eggs found in faecal samples

\begin{tabular}{|c|c|c|c|}
\hline Species & Size & Morphological features & Refs \\
\hline $\begin{array}{l}\text { Eucoleus } \\
\text { aerophilus }\end{array}$ & $\begin{array}{l}60-85 \mu \mathrm{m} \\
\text { long } \\
25-40 \mu \mathrm{m} \\
\text { wide }\end{array}$ & $\begin{array}{l}\text { Bipolar plugs asymmetrical, outer shell densely striated and with presence of a network of anastomosing } \\
\text { ridges }\end{array}$ & {$[37,93,105]$} \\
\hline $\begin{array}{l}\text { Eucoleus } \\
\text { boehmi }\end{array}$ & $\begin{array}{l}50-60 \mu \mathrm{m} \\
\text { long } \\
30-35 \mu \mathrm{m} \\
\text { wide }\end{array}$ & Tiny pits on the surface of the egg wall & {$[37,90,93]$} \\
\hline Trichuris spp. & $\begin{array}{l}70-80 \mu \mathrm{m} \\
\text { long } \\
30-50 \mu \mathrm{m} \\
\text { wide }\end{array}$ & Symmetrical, presence of ringed thickening at the base of the bipolar plugs, smooth egg wall & {$[93,131]$} \\
\hline $\begin{array}{l}\text { Aoncotheca } \\
\text { putorii }\end{array}$ & $\begin{array}{l}56-72 \mu \mathrm{m} \\
\text { long } \\
23-32 \mu \mathrm{m} \\
\text { wide }\end{array}$ & $\begin{array}{l}\text { Bipolar plugs asymmetrical, sides of shell wall nearly parallel, longitudinal network of anastomosing } \\
\text { ridges on shell wall surface }\end{array}$ & {$[37,93]$} \\
\hline
\end{tabular}




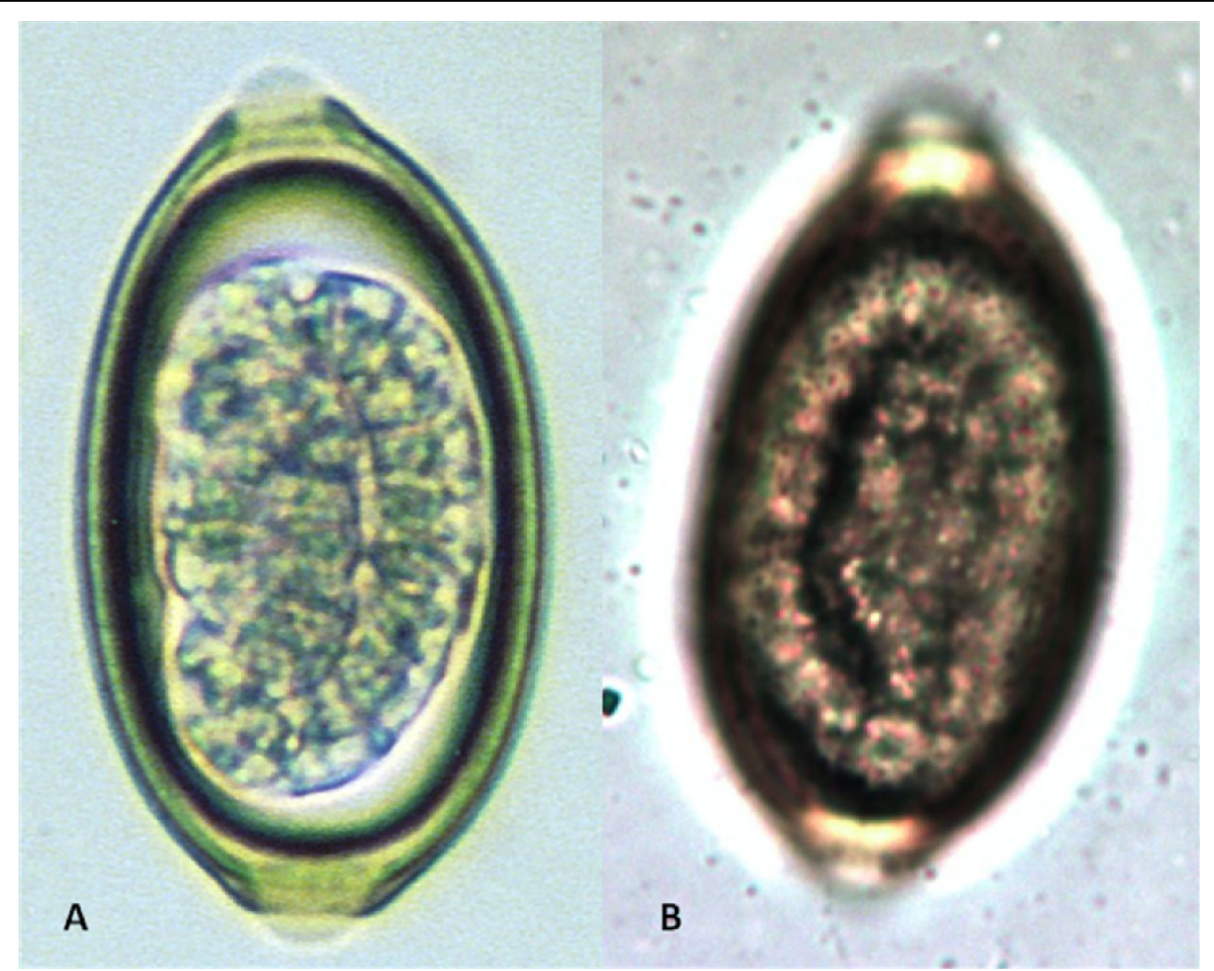

Figure 9 Floatation with Zinc Sulphate: eggs of Eucoleus boehmi (A) showing the pitted wall surface (B).

RFLP, PCR amplifications with species-specific primers or with universal primers yielding species-specific amplicons $[132,133]$. The usefulness of molecular tools for identifying $D$. immitis has been recently demonstrated in epidemiological and clinical studies $[87,134,135]$.

\section{Treatment and control: what's new?}

Due to a perception of lack of importance (with the exception of D. immitis), there has been very little study until the last decade with respect to anthelmintic efficacies for the treatment of the cardiopulmonary parasites in dogs and cats. Recommended treatment protocols for the most part have been anecdotal and empirically derived.

Even though several therapeutic options have been investigated for the treatment of aelurostrongylosis and angiostrongylosis, benzimidazoles and macrocyclic lactones have been widely used in different formulations to treat these infections. In suspension or in tablet form, fenbendazole, administered daily for 5 days at $20 \mathrm{mg} / \mathrm{kg}$ or 15 days at $50 \mathrm{mg} / \mathrm{kg}$ was effective in the treatment of feline aelurostrongylosis [136,137]. Administration of fenbendazole at a dosage of $50 \mathrm{mg} / \mathrm{kg}$ per os daily for 3 consecutive days has been also reported to be effective in the treatment of cats infected with $A$. abstrusus $[138,139]$. An $18.75 \%$ fenbendazole oral paste has become licensed for the treatment of A. abstrusus infection in cats at this dosage in the UK. Other anthelmintics have also been tested against $A$. abstrusus, with disappointing results involving controversial or inconsistent efficacies, issues of palatability and inconvenient dosing schedules, toxicosis, side effects and off label dosages [97,140,141]. For instance, ivermectin has been used off label to treat cats infected with $A$. abstrusus, however, limited activity and/or the need for subsequent administrations $[137,142,143]$ and possible life-threatening side effects in young animals [144] discourage its use as a treatment for this parasitic infection. Recently, the efficacy and safety of the UK formulation of fenbendazole (18.75\%) oral paste has been compared with those of two spot-on formulations, one containing the neonicotinoid ectoparasiticide imidacloprid $10 \%$ and the macrolactone endo-ectoparasiticide moxidectin $1 \%$, and the other contained the anthelmintic octadepsipeptide emodepside $2.1 \%$ and the cestodicide/trematodicide praziquantel $8.6 \%[145,146]$. The three formulations were found to be safe and effective in the treatment of aelurostrongylosis in naturally infected cats. The emodepside $2.1 \%$ /praziquantel $8.6 \%$ spot-on and the fenbendazole paste showed similar activities while the imidacloprid $10 \%$ /moxidectin $1 \%$ spot-on was superior in efficacy compared to the other two preparations $[145,146]$.

An analogous spot-on formulation containing imidacloprid $10 \%$ /moxidectin $2.5 \%$ was shown to be effective for both therapy and prevention of canine angiostrongylosis. 


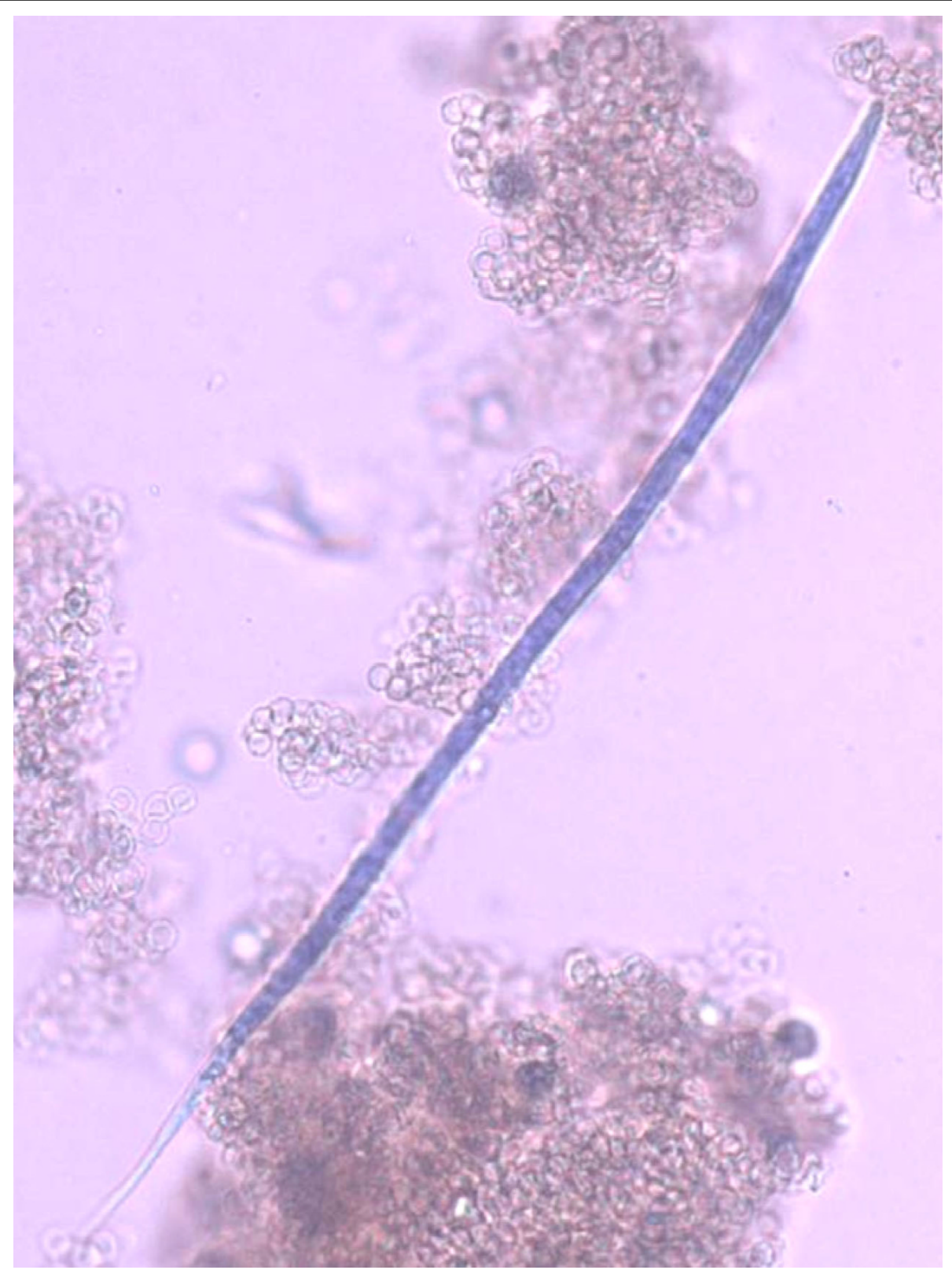

Figure 10 Knott's method: Dirofilaria immitis microfilaria.

A single application of this formulation demonstrated an efficacy $(85.2 \%)$ similar to that observed in dogs treated with fenbendazole (91.3\%) daily at $25 \mathrm{mg} / \mathrm{kg}$ for 20 days [147], and also equal to that achieved previously (84.8\%) using milbemycin oxime $(0.5 \mathrm{mg} / \mathrm{kg})$ given orally once a week for 4 weeks [148]. The same imidacloprid 10\%/ moxidectin $2.5 \%$ spot-on formulation has been evaluated for its effective and safe larvicidal activity in dogs experimentally infected with $A$. vasorum [149]. A single topical application was $100 \%$ effective in the elimination of fourth stage larvae (L4) and pre-adults of the parasite, thus preventing patent infections. Use of this topical anthelmintic would likely prevent or, at the least, minimize the potential for severe cardiopulmonary tissue damage in dogs due to $A$. vasorum infection. On this basis, a monthly anthelmintic administration with this formulation would be a powerful tool for preventing the establishment of adult stages of $A$. vasorum and the clinical onset of the disease, especially in endemic areas [149]. Another option for prevention of canine angiostrongylosis is milbemycin oxime. An efficacy of $85 \%$ was reported in dogs given milbemycin oxime $(0.5 \mathrm{mg} / \mathrm{kg})$ at 30 and 60 days after experimental infection with $A$. vasorum [148]. 


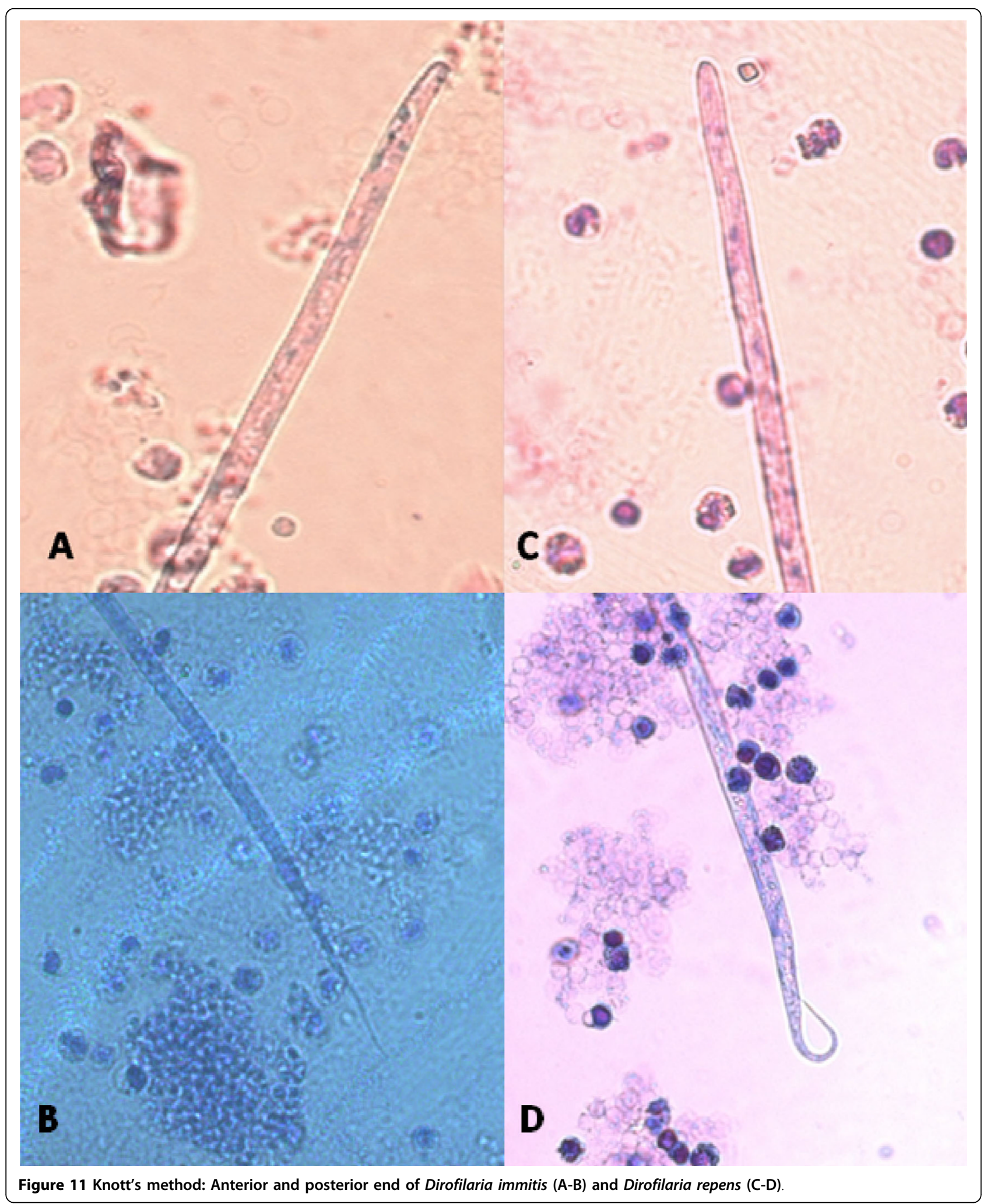




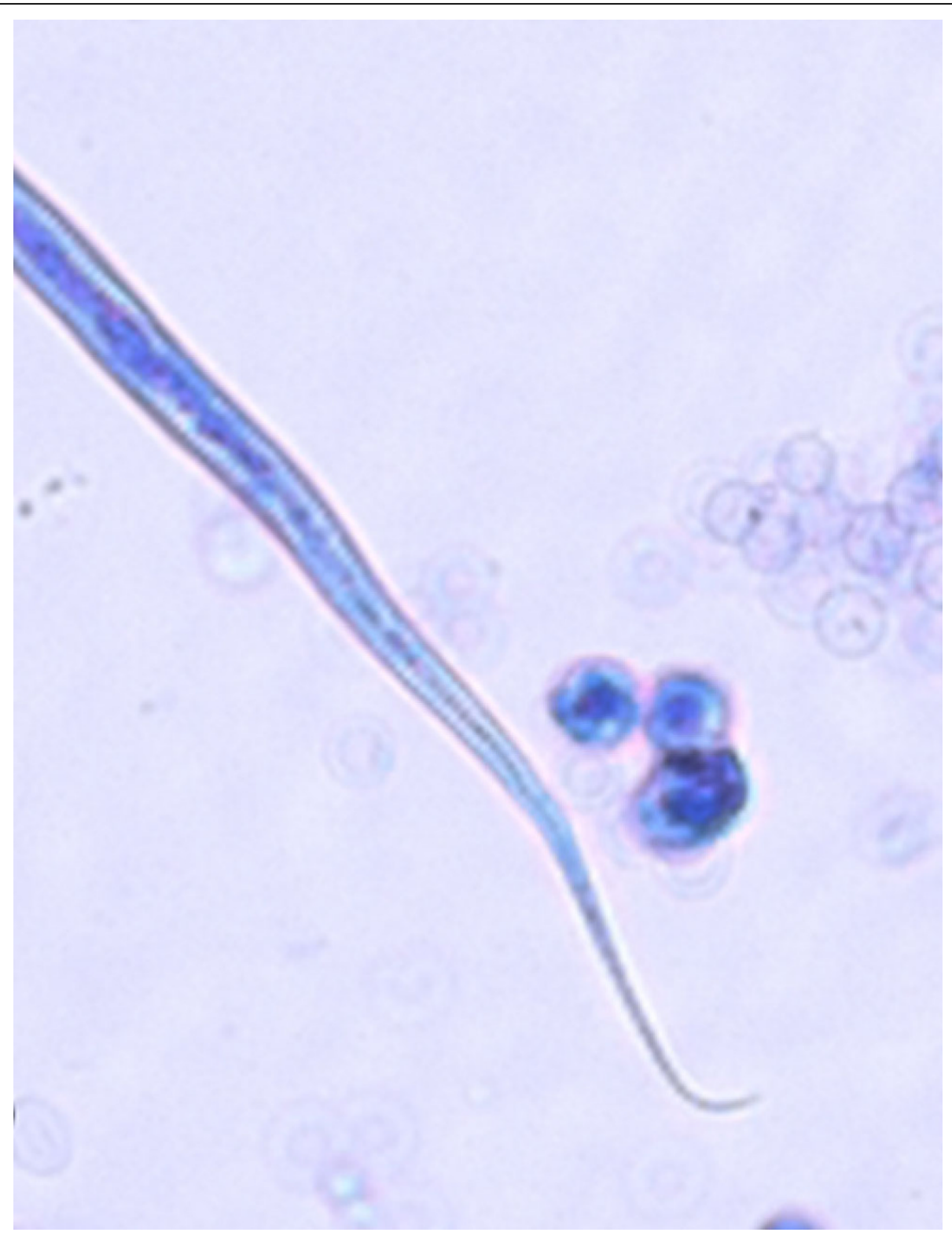

Figure 12 Knott's method: Posterior end of Acanthocheilonema (= Dipetalonema) reconditum

Various anthelmintics have been used to treat dogs infected with $C$. vulpis. A single topical application of the imidacloprid $10 \%$ /moxidectin $2.5 \%$ spot-on was found to have an efficacy of $100 \%$ in dogs experimentally infected with C. vulpis [150]. A single oral dose of milbemycin oxime $(0.5 \mathrm{mg} / \mathrm{kg})$ had an efficacy of 98-99\% when used in the treatment of dogs experimentally infected with C. vulpis [151]. Other treatment options for which efficacy data is unknown but have been reported to be effective when used in cases of

Table 5 Major filarioid nematodes affecting dogs and cats: differential features (derived from Refs 106 and 131) of microfilariae found in blood samples by Knott's examination

\begin{tabular}{lllll}
\hline Species & Length $(\boldsymbol{\mu m})$ & Width $(\boldsymbol{\mu m})$ & Posterior end & Anterior end \\
\hline Dirofilaria immitis & $260-340$ & $5-7.5$ & Straight and thin & Gently tapered \\
Dirofilaria repens & $325-380$ & $5-8$ & Umbrella-like & Blunt \\
Acanthocheilonema reconditum & $240-290$ & $4.5-5.5$ & Button-hooked & Blunt, with a prominent cephalic hook \\
\hline
\end{tabular}


natural $C$. vulpis infection in dogs include fenbendazole (25-50 mg/kg, oral, daily for 3-14 days) and febantel (14 $\mathrm{mg} / \mathrm{kg}$, oral, daily for 7 days) $[108,110,152]$.

In summary, options that have been used successfully to treat dogs infected with $A$. vasorum or $C$. vulpis include oral fenbendazole, febantel and milbemycin oxime and topical moxidectin-imidacloprid. Oral fenbendazole and topical moxidectin/imidacloprid and emodepside/praziquantel have been used to treat cats infected with $A$. abstrusus. In addition to efficacy, choice of anthelmintic may be influenced by such issues as ease of administration and whether a single or multiple treatments are required. Administration of oral anthelmintics may be difficult in fractious animals (especially cats) or animals that are depressed or moribund.

The least and most investigated of the cardiopulmonary nematodes concerning anthelmintic treatment are $E$. aerophilus and $D$. immitis, respectively. Little information has been published on anthelmintic treatment of capillariosis. Oral fenbendazole $(50 \mathrm{mg} / \mathrm{kg}$, daily for 14 days) was reported to be effective in the treatment of one dog infected with E. aerophilus [35]. Subcutaneous injection of abamectin $(0.3 \mathrm{mg} / \mathrm{kg}$, repeated in 14 days $)$ appeared to be effective in the treatment of a cat infected with $E$. aerophilus [32]. Given the lack of published reports on the treatment of feline and canine $E$. aerophilus infection, further studies are warranted to evaluate the efficacy and safety of anthelmintics against this lungworm.

With regard to $D$. immitis, the arsenical melarsomine dihydrochloride is the most commonly used adulticide, administered as an intramuscular injection $(2.5 \mathrm{mg} / \mathrm{kg})$ either in a two-dose (first intramuscular injection followed by the second $24 \mathrm{hr}$ later) or three-dose (first injection followed by the two-dose protocol 4-6 weeks later) protocol. In order to minimize the likelihood of inducing potentially fatal pulmonary thromboembolism after the death of the heartworms, the dog must be placed on strict exercise restriction (i.e. cage rest) during and for 4-6 weeks after the treatment period. The threedose protocol should be used in the treatment of dogs where there is significant risk of post-treatment pulmonary thromboembolism, however, current American Heartworm Society guidelines recommend the threeinjection protocol be used in the treatment of all infected dogs [153]. Macrocyclic lactones also have shown some activity as adulticides, although the American Heartworm Society recommends that the extra label use of these compounds as a primary adulticide should be discouraged [153]. As an example, experimental trials have demonstrated that ivermectin has some efficacy as an adulticide if administered monthly at the preventive dosage of $6-12 \mathrm{mcg} / \mathrm{kg}$ for at least $16-30$ months [154]. However, cardiopulmonary damage during this prolonged treatment period continues which may significantly affect the chances for a full clinical recovery $[155,156]$. In any case, in clinical cases which do not require an immediate treatment, the administration of a macrocyclic lactone for up to 6 months before administration of melarsomine can be beneficial. Such pre-treatment results in the reduction of adult worm mass and allows any immature worms present to fully mature at which time they are optimally susceptible to adulticide [92,157].

Use of the melarsomine adulticidal therapy in infected cats is considered an option only as a last resort due to the complexities of the infection in feline patients. Indeed, there is little data on the efficacy of melarsomine, which is not recommended in these animals due to a narrow therapeutic index. Studies have shown that melarsomine is toxic to cats at doses as low as $3.5 \mathrm{mg} /$ $\mathrm{kg}[92,158,159]$. Ivermectin has also shown some activity as an adulticide for use in cats. In particular, when administered per os at $24 \mathrm{mg} / \mathrm{kg}$ monthly for 24 months, the molecule may achieve a $65 \%$ reduction of worm burden [160].

A new strategy for the control of heartworms targets their Wolbachia bacterial endosymbionts. Treatment with tetracycline antibiotics has been reported to prevent larval development, inhibit embryogenesis in adult worms and eventually lead to the death of the adult stage of several filarial species [161,162]. Administration of both doxycycline and ivermectin for several months prior to or in the place of melarsomine treatment can eliminate adult worms with a reduced risk of thromboembolism. Thus, it is suggested that doxycycline has potential utility in the heartworm adulticide therapy for dogs and that a combination of doxycycline and ivermectin is adulticidal in dogs infected with $D$. immitis $[92,163,164]$.

Given the severe pathogenic role of $D$. immitis heartworm, chemoprophylactic approaches are the best options for preventing the infection especially in endemic areas. The most widely used preventive drugs belong to the macrocyclic lactones class (avermectins and milbemycins), which are able to kill third and fourth larval stages of $D$. immitis [92]. Preventative protocols are based on the administration of anthelmintics once a month during the season of activity of vectors: oral ivermectin at $6 \mathrm{mcg} / \mathrm{kg}$, milbemycin oxime at $500 \mathrm{mcg} / \mathrm{kg}$ and moxidectin at $3 \mathrm{mcg} / \mathrm{kg}$, or topical selamectin at 6 $\mathrm{mg} / \mathrm{kg}[92,160]$. Regardless of the anthelmintic chosen, the administration should start within a month after the beginning of the mosquito season and finish within 1 month after the end of the season. Nevertheless, in endemic areas there is the recommendation to treat year-round with ivermectin, milbemycin oxime or selamectin, which provides protection when administered 
on a regular basis even if begun 3 months after infection $[92,153,165]$. In some countries there is also the option to use injectable moxidectin sustained-release formulation to protect dogs for the entire vector season $[166,167]$.

The spot-on formulation containing imidacloprid 10\%/ moxidectin $1 \%$ may be successfully used for the prevention of D. immitis infection in cats [168].

\section{Conclusion remarks and future avenues}

In conclusion, the purpose of this article was to provide an overview of current knowledge for the most important heartworm and lungworm infections of dogs and cats in Europe. In the past ten years the geographic range of these parasitic nematodes has expanded and new endemic foci in areas previously free or considered at minimal transmission risk has occurred. As a consequence, the number of reports of cardiopulmonary nematode infection in dogs and cats has greatly increased. There is a need to enhance the awareness of veterinary practitioners and diagnostic laboratories of the possibility of heartworm and lungworm infections, and to improve diagnostic means and control measures. Some copromicroscopic methods (e.g. Baermann technique) are not often applied in current practice, although cats and dogs may show clinical signs suggestive of parasitoses caused by cardiopulmonary worms. It is thus crucial that the Baermann method becomes a routine diagnostic test choice when dogs and cats present with signs suggestive of these infections [21,93]. Additionally, the Knott's method and antigen test kits are not used in those areas where $D$. immitis is erroneously thought to be absent. The key example of central-southern Italy in which the heartworm has recently been found should provide food for thought on these emerging issues $[8,20,87]$. In the coming years veterinarians will be faced more and more with problems and challenges related to the emergence of cardiopulmonary nematodes in companion animals. This is particularly true in those geographical regions which were considered free of infection and that, conversely, have become in the past few years infected with "new pathogens", e.g. D. immitis in the south and central regions of Italy and A. vasorum in Germany and The Netherlands. Additionally, several biological and epidemiological drivers, most of them yet to be elucidated, appear to be increasing the risk of infection in dogs and cats within the stable endemic foci of these parasites, as for instance A. abstrusus in Italy and the Iberian peninsula. Lack of awareness of these changing patterns have serious implications from a clinical standpoint, given that a delay in diagnosis and treatment can lead to severe lesions and even death in infected animals. The accurate diagnosis of these infections is necessary for the timely and effective treatment which can greatly impact the prognosis for dogs and cats affected by these parasites. Nonetheless, the lack of specificity of the clinical signs of infections caused by cardiopulmonary nematodes and the difficulties in the differential diagnosis, often lead to misdiagnosis, thus animals remain infected and untreated. Therefore, heartworm and lungworms should always be included in the differential diagnosis when pets are presented with cardiopulmonary disorders. Also, European veterinarians should be aware of diagnostic techniques available and of the current epidemiological situations, e.g. having always in mind that some nematodes (e.g. A. vasorum) are indeed emerging [7], some (e.g. E. aerophilus) are occasional but present and a potential danger for human health $[20,36]$ and others (Filaroides and Oslerus) are almost absent and only sporadically reported in companion animals [169-171].

Given the impact heartworms and lungworms may have on animal health, the zoonotic potential of some of them and the trend in geographic spread, it is crucial that veterinary practitioners are aware of their importance and of appropriate diagnostic techniques and control plans.

\section{Acknowledgements}

DT is sincerely grateful to Domenico Otranto and Annunziata Giangaspero. DT and ADC are grateful to all friends and colleagues for the scientific exchange on canine and feline cardiopulmonary nematodes: Andrea Boari, Barbara Paoletti, Giovanni Aste, Raffaella lorio, Roberto Bartolini, Piermarino Milillo, Silvana Meloni, Eric Morgan, Emanuela Di Giulio, Carmelo Flavio Dimitri, Matteo Seghetti, Antonella Di Tella, Andrea Rosati, Sara Scaramucci. DT and ADC thank all students of the Faculty of Veterinary Medicine of Teramo who participate in the activities of the Team of Parasitology and Parasitic Diseases. GC gratefully acknowledges the essential contribution of technical support provided by Robert Maloney, Nicole Murphy and Sarah Ramsay. The authors thank Giuseppe Castagna for Tables 1 and 2, and Figures 1 and 2 (elaboration of the bibliographic data and process).

\section{Author details}

'Department of Comparative Biomedical Sciences, University of Teramo, Teramo, Italy. ${ }^{2}$ Department of Pathology and Microbiology, Atlantic Veterinary College, Charlottetown, PEI, Canada.

\section{Authors' contributions}

DT conceived the article and contributed to its drafting, preparation and intellectual content; ADC analysed the bibliographic data, processed the iconography and participated in drafting the article; GC contributed to the intellectual contents and inputs of the article and to its critical revision. All authors read and approved the final manuscript.

\section{Competing interests}

The authors declare that there are no competing interests and that the conceptual design, the content or any other scientific aspect have not been influenced.

Received: 27 May 2010 Accepted: 23 July 2010 Published: 23 July 2010

\section{References}

1. Blashki G, McMichael T, Karoly DJ: Climate change and primary health care. Aust Fam Physician 2007, 36:986-989.

2. Khasnis AA, Nettleman MD: Global warming and infectious disease. Arch Med Res 2005, 36:689-696. 
3. Rogers DJ, Randolph SE: Climate change and vector-borne diseases. Adv Parasitol 2006, 62:345-381.

4. Jenkins EJ, Kutz SJ, Hoberg EP, Polley L: Bionomics of larvae of Parelaphostrongylus odocoilei (Nematoda: Protostrongylidae) in experimental infected gastropod intermediate hosts. J Parasitol 2006, 92:298-305.

5. Genchi C, Rinaldi L, Mortarino M, Genchi M, Cringoli G: Climate and Dirofilaria infection in Europe. Vet Parasitol 2009, 163:286-292.

6. Morgan ER, Tomlinson A, Hunter S, Nichols T, Roberts E, Fox MT, Taylor MA: Angiostrongylus vasorum and Eucoleus aerophilus in foxes (Vulpes vulpes) in Great Britain. Vet Parasitol 2008, 154:48-57.

7. Morgan ER, Jefferies R, Krajewski M, Ward P, Shaw SE: Canine pulmonary angiostrongylosis: The influence of climate on parasite distribution. Parasitol Int 2009, 58:406-410.

8. Otranto D, Capelli G, Genchi C: Changing distribution pattern of canine vector borne diseases in Italy: Leishmaniosis vs. dirofilariosis. Parasites \& Vectors 2009, 2:S2.

9. Helm JR, Morgan ER, Jackson MW, Wotton P, Bell R: Canine angiostrongylosis: an emerging disease in Europe. Vet Emerg Crit Care 2010, 20:98-109.

10. Medlock JM, Barras I, Kerrod E, Taylor MA, Leach S: Analysis of climatic predictions for extrinsic incubation of Dirofilaria in the United Kingdom. Vector Borne Zoonotic Dis 2007, 7:4-14.

11. Kalluri S, Gilruth P, Rogers D, Szczur M: Surveillance of arthropod vectorborne infectious diseases using remote sensing techniques: a review. PLoS Pathog 2007, 26:1361-1371.

12. Genchi C, Rinaldi L, Cascone C, Mortarino M, Cringoli G: Is heartworm disease really spreading in Europe? Vet Parasitol 2005, 133:137-148.

13. Rinaldi L, Musella V, Marzatico G, Genchi C, Cringoli G: Geographical information systems in health application: experience on filariosis and other vector-borne diseases. Proceedings of the WAAVP Congress: 19-23 August 2007; Gent, Belgium Claerebout E, Vercruysse J 2007, 165.

14. Helm J, Gilleard JS, Jackson M, Redman E, Bell R: A case of Angiostrongylus vasorum in Scotland confirmed by PCR and sequence analysis. J Small Anim Pract 2009, 50:255-259.

15. Yamakawa Y, McGarry JW, Denk D, Dukes-McEwan J, MacDonald N, Mas A, McConnell F, Tatton B, Valentine EG, Wayne J, Williams JM, Hetzel U: Emerging canine angiostrongylosis in northern England: five fatal cases. Vet Rec 2009, 164:149-152.

16. Poli A, Arispici M, Mancianti F, Abramo F: Pathology of naturally acquired Angiostrongylus vasorum infection in the red fox (Vulpes vulpes). Angew Parasitol 1991, 32:121-126.

17. Poli A, Arispici M, Marconcini A, Mancianti F, de Monte D: Angiostrongylus vasorum (Baillet, 1866) in red foxes (Vulpes vulpes L.) in Italy. J Wildl Dis 1984, 20:345-346.

18. Traversa D, Torbidone A, Malatesta D, Guglielmini C: Occurrence of fatal canine Angiostrongylus vasorum infection in Italy. Vet Parasitol 2008, 152:162-166

19. Sasanelli M, Paradies P, Otranto D, Lia RP, de Caprariis D: Haemothorax associated with Angiostrongylus vasorum infection in a dog. I Small Anim Pract 2008, 49:417-420

20. Di Cesare A, Meloni S, Milillo P, Castagna G, Otranto D, Paoletti B, Bartolini R, Avolio S, Traversa D: Feline and canine cardio-pulmonary nematodes in central and southern Italy. Proceedings of the XXVI SoIPa Congress: 22-25 June 2010; Perugia, Italy 307.

21. Traversa D, Guglielmini C: Feline aelurostrongylosis and canine angiostrongylosis: a challenging diagnosis for two emerging verminous pneumonia infections. Vet Parasitol 2008, 157:163-174.

22. Payo-Puente P, Botelho-Dinis M, Carvaja Urueña AM, Payo-Puente M, Gonzalo-Orden JM, Rojo-Vazquez FA: Prevalence study of the lungworm Aelurostrongylus abstrusus in stray cats of Portugal. J Feline Med Surg 2008, 10:242-246.

23. Traversa D, Di Cesare A, Milillo P, lorio R, Otranto D: Aelurostrongylus abstrusus in a feline colony from central Italy: clinical features, diagnostic procedures and molecular characterization. Parasitol Res 2008, 103:1191-1196.

24. Traversa D, Lia RP, lorio R, Boari A, Paradies P, Capelli G, Avolio S, Otranto D: Diagnosis and risk factors of Aelurostrongylus abstrusus (Nematoda, Strongylida) infection in cats from Italy. Vet Parasitol 2008, 153:182-186.

25. Unterer S, Deplazes P, Arnold P, Flückiger M, Reusch CE, Glaus TM: Spontaneous Crenosoma vulpis infection in 10 dogs: laboratory, radiographic and endoscopic findings. Schweiz Arch Tierheilkd 2002, 144:174-179.

26. Madeira de Carvalho LM, Pereira da Fonseca LM, Gomes L, Meireles JM: Lungworms in domestic and wild carnivores in Portugal: rare parasites or rarely diagnosed? Proceedings of the Bayer Angiostrongylosis Forum, 19th Annual Congress of the European College of Veterinary Internal Medicine Companion Animals: 9 September 2009; Porto, Portugal Bayer Animal Health $\mathrm{GmbH}$ 2009, 28.

27. Barutzki D, Schaper R: Natural infections of Angiostrongylus vasorum and Crenosoma vulpis in dogs in Germany (2007-2009). Parasitol Res 2009, 105:39-48.

28. Macpherson $\mathrm{CN}$ : Human behaviour and the epidemiology of parasitic zoonoses. Int J Parasitol 2005, 35:1319-1331.

29. Patz JA, Graczyk TK, Geller N, Vittor AY: Effects of environmental change on emerging parasitic diseases. Int J Parasitol 2000, 30:1395-1405.

30. Prociv P, Carlisle MS: The spread of Angiostrongylus cantonensis in Australia. Southeast Asian J Trop Med Public Health 2001, 32:126-128.

31. Tomlinson AJ, Taylor M, Roberts E: Angiostrongylus vasorum in canids. Vet Rec 2006, 158:858-863.

32. Barrs VR, Martin P, Nicoll RG, Beatty JA, Malik R: Pulmonary cryptococcosis and Capillaria aerophila infection in an FIV-positive cat. Aust Vet J 2000, 78:154-158.

33. Foster SF, Martin P, Allan GS, Barrs VR, Malik R: Lower respiratory tract infections in cats: 21 cases (1995-2000). J Feline Med Surg 2004, 6:167-180.

34. Foster SF, Martin P, Braddock JA, Malik R: A retrospective analysis of feline bronchoalveolar lavage cytology and microbiology (1995-2000). J Feline Med Surg 2004, 6:189-198.

35. Burgess H, Ruotsalo K, Peregrine AS, Hanselman B, Abrams-Ogg A: Eucoleus aerophilus respiratory infection in a dog with Addison's disease. Can Vet J 2008, 49:389-392.

36. Lalosević D, Lalosević V, Klem I, Stanojev-Jovanović D, Pozio E: Pulmonary capillariasis miming bronchial carcinoma. Am J Trop Med Hyg 2008, 78:14-16.

37. Traversa D, Di Cesare A, Milillo P, Iorio R, Otranto D: Infection by Eucoleus aerophilus in dogs and cats: is another extra-intestinal parasitic nematode of pets emerging in Italy? Res Vet Sci 2009, 87:270-272.

38. Trotz-Williams LA, Trees AJ: Systematic review of the distribution of the major vector-borne parasitic infections in dogs and cats in Europe. Vet Rec 2003, 152:97-105.

39. Harrus S, Baneth G: Drivers for the emergence and re-emergence of vector-borne protozoal and bacterial diseases. Int J Parasitol 2005, 35:1309-1318.

40. Williams JF, Lindemann B, Padgett GA, Smith OL: Angiostrongylosis in a greyhound. J Am Vet Med Assoc 1985, 186:1101-1103.

41. Tebb Al, Johnson VS, Irwin PJ: Angiostrongylus vasorum (French heartworm) in a dog imported into Australia. Aust Vet J 2007, 85:23-28.

42. Glaser B, Gothe R: Imported arthropod-borne parasites and parasitic arthropods in dogs. Species spectrum and epidemiologic analysis of the cases diagnosed in 1995/96. Tierarztl Prax Ausg K Klientiere Heimtiere 1998, 26:40-46.

43. Svobodova V, Misonova P: The potential risk of Dirofilaria immitis becoming established in the Czech Republic by imported dogs. Vet Parasitol 2005, 128:137-140.

44. Romi R: History and updating on the spread of Aedes albopictus in Italy. Parassitologia 1995, 37:99-103.

45. Pietrobelli M: Importance of Aedes albopictus in veterinary medicine. Parassitologia 2008, 50:113-115.

46. Arnold $P$, Venzin I, Fluckiger $M$, Suter $P$ : What are you diagnosing? Which measures are you suggesting? Schweiz Arch Tierheilkd 1987, 7:369-372.

47. Miró G, Montoya A, Jiménez S, Frisuelos C, Mateo M, Fuentes I: Prevalence of antibodies to Toxoplasma gondii and intestinal parasites in stray, farm and household cats in Spain. Vet Parasitol 2004, 126:249-255.

48. Hamilton JM: Aelurostrongylus abstrusus. Infestation of the Cat. Vet Rec 1963, 75:417-422.

49. Gregersen P: Ollulanus tricuspis (Leuckart 1865). Round worms of cats. Lungworm of cats (Aelurostrongylus abstrusus). Dansk Veterinaertidsskrift 1994, 15:673-681.

50. Robben SR, le Nobel WE, Döpfer D, Hendrikx WM, Boersema JH, Fransen F, Eysker ME: Infections with helminths and/or protozoa in cats in animal shelters in the Netherlands. Tijdachr Diergeneeskd 2004, 129:2-6. 
51. Fogarty U, Dodd K: Aelurostrongylosis in a kitten: a case report. Ir Vet J 1980, 8:107-109

52. Epe C, Coati N, Schnieder T: Results of parasitological examinations of faecal samples from horses, ruminants, pigs, dogs, cats, hedgehogs and rabbits between 1998 and 2002. Dtsch Tierarztl Wochenschr 2004, 111:243-247

53. Taubert A, Pantchev N, Vrhovec MG, Bauer C, Hermosilla C: Lungworm infections (Angiostrongylus vasorum, Crenosoma vulpis, Aelurostrongylus abstrusus) in dogs and cats in Germany and Denmark in 2003-2007. Vet Parasitol 2009, 5:175-180

54. Labrique $Y$, Gouffaux M: Pulmonary aelurostrongylosis in a cat. Ann Vet Med 1974, 8:539-550.

55. Berg C: Aelurostrongylus abstrusus infection in cats. A case report. Norsk Vet 1979, 9:503-507.

56. Kassai T: Lungworms in carnivores. Magyar All Lapja 1992, 10:541.

57. Grabarevic S, Curic A, Tustonja B, Artukovic Z, Šimec K, Ramadan K, Zivicnjak T: Incidence and regional distribution of the lungworm Aelurostrongylus abstrusus in cats in Croatia. Vet Arch 1999, 69:279-287.

58. Haralampides ST: Contribution to the study of cat's parasites and their public health importance. Hellenike Kteniatrike 1978, 3:117-119.

59. Barutzki D, Schaper R: Endoparasites in dogs and cats in Germany 19992002. Parasitol Res 2003, 90:148-150.

60. Rinaldi L, Calabria G, Carbone S, Carrella A, Cringoli G: Crenosoma vulpis in dog: first case report in Italy and use of the FLOTAC technique for copromicroscopic diagnosis. Parasitol Res 2007, 101:1681-1684.

61. Reilly GA, McGarry JW, Martin M, Belford C: Crenosoma vulpis, the fox lungworm, in a dog in Ireland. Vet Rec 2000, 146:764-765

62. MCGarry JW, Martin M, Cheeseman MT, Payne-Johnson CE: Crenosoma vulpis, the fox lungworm, in dogs. Vet Rec 1995, 137:271-272.

63. Mircean V, Titilincu A, Vasile C: Prevalence of endoparasites in household cat (Felis catus) populations from Transylvania (Romania) and association with risk factors. Vet Parasitol 2010, 171:163-166.

64. Burgu A, Sarimehmetoğlu O: Aelurostrongylus abstrusus infection in two cats. Vet Rec 2004, 154:602-604

65. Guiraud C: L'aelurostrongylose du chat. Prat Méd Chir Anim 1993, 28:277-283.

66. Dzimira S, Popioek M: Case of aelurostrongylosis in a domestic cat. Med Weter 2005, 61:894-895.

67. Staebler S, Ochs H, Steffen F, Naegeli F, Borel N, Sieber-Ruckstuhl N, Deplazes P: Autochthonous infections with Angiostrongylus vasorum in dogs in Switzerland and Germany. Schweiz Arch Tierheilkd 2005, 147:121-127.

68. Åblad B, Christensson D, Lind EO, Agren E, Morner T: Angiostrongylus vasorum etablerad i Sverige. Svensk Veterinärtidning 2003, 12:11-15.

69. Nicolle AP, Chetboul V, Tessier-Vetzel D, Carlos Sampedrano C, Aletti E, Pouchelon JL: Severe pulmonary arterial hypertension due to Angiostrongylosus vasorum in a dog. Can Vet J 2006, 47:792-795.

70. Bourdeau P, Laboure L: Current situation of canine angiostrongylosis in France: result from a national survey with veterinary clinics. Proceedings of the Bayer Angiostrongylosis Forum, 19th Annual Congress of the European College of Veterinary Internal Medicine - Companion Animals: 9 September 2009; Porto, Portugal Bayer Animal Health GmbH 2009, 30.

71. van Doorn DC, van de Sande AH, Nijsse ER, Eysker M, Ploeger HW: Autochthonous Angiostrongylus vasorum infection in dogs in The Netherlands. Vet Parasitol 2009, 162:163-166.

72. Papazahariadou M, Founta A, Papadopoulos E, Chliounakis S, AntoniadouSotiriadou K, Theodorides Y: Gastrointestinal parasites of shepherd and hunting dogs in the Serres Prefecture, Northern Greece. Vet Parasitol 2007, 148:170-173

73. Brennan SF, McCarthy G, McAllister H, Bassett $H$, Jones BR: Clinical signs, diagnosis and treatment of three dogs with angiostrongylosis in Ireland. Ir Vet J 2004, 57:103-109.

74. Pantchev N, Schaper R, Limousin S, Norden N, Weise M, Lorentzen L: Occurrence of Dirofilaria immitis and tick-borne infections caused by Anaplasma phagocytophilum, Borrelia burgdorferi sensu lato and Ehrlichia canis in domestic dogs in France: results of a countrywide serologic survey. Parasitol Res 2009, 105:101-114.

75. Bucklar H, Scheu U, Mossi R, Deplazes P: Breitet sich in der Sudschweiz die Dirofilariose beim Hund aus? Schw Arch Tierheilk 1998, 140:255-260
76. Solano-Gallego L, Llull J, Osso M, Hegarty B, Breitschwerdt E: A serological study of exposure to arthropod-borne pathogens in dogs from northeastern Spain. Vet Res 2006, 37:231-244.

77. Montoya JA, Morales M, Ferrer O, Molina JM, Corbera JA: The prevalence of Dirofilaria immitis in Gran Canaria, Canary Islands, Spain (1994-1996). Vet Parasitol 1998, 75:221-226.

78. Miterpáková M, Antolová D, Hurníková Z, Dubinský P: Dirofilariosis in Slovakia - a new endemic area in Central Europe. Helmintologia 2008, 45:20-23.

79. Svobodová Z, Svobodová V, Genchi C, Forejtek P: The first report of autochthonous dirofilariosis in dogs in the Czech Republic. Helmintologia 2006, 43:242-245.

80. Jacsó O, Mándoki M, Majoros G, Pétsch M, Mortarino M, Genchi C, Fok E: First autochthonous Dirofilaria immitis (Leidy, 1856) infection in a dog in Hungary. Helmintologia 2009, 46:159-161.

81. Tasić A, Rossi L, Tasić S, Miladinović-Tasić N, llić T, Dimitrijević S: Survey of canine dirofilariasis in Vojvodina, Serbia. Parasitol Res 2008, 103:1297-1302.

82. Olteanu G: Dirofilariosis in man and animals in Romania. Proceedings of VII European Multicolloquium of Parasitology: 2-6 September 1996; Parma, Italy Parassitologia 1996, 38:360.

83. Georgieva D, Kirkova Z, Ivanov A: A study on the incidence and diagnostic of dirofilariosis (heartworm disease) in carnivores. Bulgarian $J$ Vet Med 2001, 4:231-236.

84. Lazri T, Duscher G, Edelhofer R, Bytyci B, Gjino P, Joachim A: Arthropodborne parasites of dogs, especially Leishmania, in the Kosovo and Albania. Wien Klin Wochenschr 2008, 120:54-58.

85. Papazahariadou MG, Koutinas AF, Rallis TS, Haralabidis ST: Prevalence of microfilaemia in episodic weakness and clinically normal dogs belonging to hunting breeds. J Helminthol 1994, 68:243-245.

86. Founta A, Theodoridis Y, Frydas S, Chliounakis S: The presence of filarial parasites of dogs in Serrae Province. Bull Hellenic Vet Med Soc 1999, 50:315-320.

87. Traversa D, Aste G, Milillo P, Capelli G, Pampurini F, Tunesi C, Santori D, Paoletti B, Boari A: Autochthonous foci of canine and feline infections by Dirofilaria immitis and Dirofilaria repens in central Italy. Vet Parasitol 2010, 169:128-132.

88. Doganay A, Biyikoglu G: The filarial nematodes in dogs. Etlik Vet Mikrob Derg 1992, 7:127-139.

89. Thomas RE: A case of canine heartworm disease (Dirofilaria immitis) in the UK. Vet Rec 1985, 117:14-15.

90. Bowman DD: Respiratory System Parasites of the Dog and Cat (Part I): Nasal Mucosa and Sinuses, and Respiratory Parenchyma. Companion and Exotic Animal Parasitology, International Veterinary Information Service 2000.

91. Bowman DD: Respiratory System Parasites of the Dog and Cat (Part II): Trachea and Bronchi, and Pulmonary Vessels. Companion and Exotic Animal Parasitology, International Veterinary Information Service 2000.

92. McCall JW, Genchi C, Kramer LH, Guerrero J, Venco L: Heartworm disease in animals and humans. Adv Parasitol 2008, 66:193-285.

93. Conboy GA: Helminth parasites of the canine and feline respiratory tract. Vet Clin North Am Small Anim Pract 2009, 39:1109-1126.

94. Koch J, Willesen JL: Canine pulmonary angiostrongylosis: an update. Vet $J$ 2009, 179:348-359

95. Schmitz S, Moritz A: Chronic disseminated intravascular coagulopathy in a dog with lungworm infection. Schweiz Arch Tierheilkd 2009, 151:281-286.

96. Denk D, Matiasek K, Just FT, Hermanns W, Baiker K, Herbach N, Steinberg T, Fischer A: Disseminated angiostrongylosis with fatal cerebral haemorrhages in two dogs in Germany: a clinical case study. Vet Parasitol 2009, 160:100-108.

97. Scott DW: Current knowledge of Aelurostrongylus abstrusus in the cat. Cornell Vet 1972, 63:483-500.

98. Lautenslaugther JP: Internal helminths of cats. Vet Clin North Am Small Anim Pract 1976, 6:353-365.

99. Payo-Puente P, Diez A, Gonzalo-Orden JM, Notomi MK, Rodríquez Altónaga JA, Rojo-Vázquez FA, Orden AM: Computed Tomography in cats infected by Aelurostrongylus abstrusus: 2 clinic cases. Intern J Appl Res Vet Med 2005, 3:339-343.

100. Naylor JR, Hamilton JM, Weathereley AJ: Changes in the ultrastructure of feline pulmonary arteries following in infection with the lungworm Aelurostrongylus abstrusus. Br Vet J 1984, 140:181-190. 
101. Pechman RD: Respiratory parasites. The cat: diseases and clinical management Churchill Livingstone, New YorkSherding RD 1995, 613-622.

102. Ribeiro VM, Lima WS: Larval production of cats infected and re-infected with Aelurostrongylus abstrusus (Nematoda: Protostrongylidae). Rev Méd Vét 2001, 152:815-829.

103. Tüzer E, Toparlak M, Gargili A, Keles V, Ulutaş Estagil M: A case of Aelurostrongylus abstrusus infection in a cat in İstanbul, Turkey and its treatment with moxidectin and levamisole. Turk J Vet Anim Sci 2002 26:411-414.

104. Holmes PR, Kelly JD: Capillaria aerophila in the domestic cat in Australia. Aust Vet J 1973, 49:472-473

105. Bowman DD, Hendrix CM, Lindsay DS, Barr SC: Feline Clinical Parasitology Blackwell Science Company, lowa State University 2002, 267-271.

106. Taylor MA, Coop RL, Wall RL: Veterinary Parasitology Blackwell Publishing, 3 2007.

107. Shaw DH, Conboy GA, Hogan PM, Horney BS: Eosinophilic bronchitis caused by Crenosoma vulpis infection in dogs. Can Vet J 1996, 37:361-363.

108. Cobb MA, Fisher MA: Crenosoma vulpis infection in a dog. Vet Rec 1992, 130:452.

109. Kriegleder H, Barutzki D: Lungenwurmbefall (Crenosoma vulpis) bei Hund. Kleintierpraxis 1988, 33:17-20.

110. Petersen EN, Barr SC, Gould WJ, Beck KA, Bowman DW: Use of fenbendazole for treatment of Crenosoma vulpis infection in a dog. J Am Vet Med Assoc 1993, 202:1483-1484.

111. Neiger R, Gaschen F, Kaufmann H: What is your diagnosis? Chronic cough and fever in a female dog. Schweiz Arch Tierheilkd 1994, 136:193-195.

112. Reilly GAC, McGarry JW, Martin M, Belford C: Crenosoma vulpis, the fox lungworm, in a dog in Ireland. Vet Rec 2000, 146:764-765.

113. Skrjabin Kl, Shikhovalova NP, Orlov IV: Trichocephalidae and Capillaridae of Animals and Man and Diseases Caused by Them. Essentials of Nematology Moscow: Academy of Sciences of USSR 1957.

114. Coudert J, Despeignes J, Battesti MR: Case of pulmonary capillariasis. Bull Soc Pathol Exot Filiales 1972, 65:841-848

115. Aftandelians R, Raafat F, Taffazoli M, Beaver PC: Pulmonary capillariasis in a child in Iran. Am J Trop Med Hyg 1977, 26:64-71.

116. Lee AC, Montgomery SP, Theis JH, Blagburn BL, Eberhard ML: Public health issues concerning the widespread distribution of canine heartworm disease. Trends Parasitol 2010, 26:168-173.

117. Theis JH: Public health aspects of dirofilariasis in the United States. Vet Parasitol 2005, 133:157-180.

118. Simón F, López-Belmonte J, Marcos-Atxutegi C, Morchón R, MartínPacho JR: What is happening outside North America regarding human dirofilariasis? Vet Parasitol 2005, 133:181-189.

119. Milanez de Campos JR, Barbas CS, Filomeno LT, Fernandez A, Minamoto H, Filho JV, Jatene FB: Human pulmonary dirofilariasis: analysis of 24 cases from São Paulo, Brazil. Chest 1997, 112:729-733.

120. Bielawski BC, Harrington D, Joseph E: A solitary pulmonary nodule with zoonotic implications. Chest 2001, 119:1250-1252.

121. Stephen HG: Migrating worms. "Principle and Practice of Clinical Parasitology" John Wiley and Sons, Chichester, UKStephen HG, Richard DP 2001, 535-551.

122. Kim MK, Kim CH, Yeom BW, Park SH, Choi SY, Choi JS: The first human case of hepatic dirofilariasis. J Korean Med Sci 2002, 17:686-690.

123. Willard MD, Roberts RE, Allison N, Grieve RB, Escher K: Diagnosis of Aelurostrongylus abstrusus and Dirofilaria immitis infections in cats from a human shelter. J Am Vet Med Assoc 1988, 192:913-916.

124. Calvert CA, Mandell CP: Diagnosis and management of feline heartworm disease. J Am Vet Med Assoc 1982, 180:550-552.

125. Pechman RD Jr: Newer knowledge of feline bronchopulmonary disease. Vet Clin North Am Small Anim Pract 1984, 14:1007-1019.

126. Humm K, Adamantos S: Is evaluation of a faecal smear a useful technique in the diagnosis of canine pulmonary angiostrongylosis? J Sm Anim Pract 2010, 51:200-203.

127. Conboy GA: Natural infection of Crenosoma vulpis and Angiostrongylus vasorum in dogs in Atlantic Canada and their treatment with milbemycin oxime. Vet Rec 2004, 155:16-18.

128. Traversa D, lorio R, Otranto D: Diagnostic and clinical implications of a nested PCR specific for ribosomal DNA of the feline lungworm Aelurostrongylus abstrusus (Nematoda, Strongylida). J Clin Microbiol 2008, 45:1811-1817.
129. Jefferies R, Morgan ER, Shaw SE: A SYBR green real-time PCR assay for the detection of the nematode Angiostrongylus vasorum in definitive and intermediate hosts. Vet Parasitol 2009 , 166:122-118.

130. Verberger-Epshtein I, Markham RJF, Sheppard JA, Stryhn H, Whitney H, Conboy G: Serologic detection of Angiostrongylus vasorum infection in dogs. Vet Parasitol 2008, 151:53-60.

131. Sloss MW, Kemp RL, Zajac AM: Veterinary Clinical Parasitology lowa State University Press, Ames, IA 1994

132. Casiraghi M, Mazzocchi C, Mortarino M, Ottina E, Genchi C: A simple molecular method for discrimination common filarial nematodes of dogs (Canis familiaris). Vet Parasitol 2006, 141:368-372.

133. Rishniw M, Barr SC, Simpson KW, Frongillo MF, Franz M, Dominguez Alpizar JL: Discrimination between six species of canine microfilariae by a single polymerase chain reaction. Vet Parasitol 2006, 135:303-314.

134. Oh HW, Jun HK, You MJ, Hayasaki M, Song KH: Ectopic migration of an adult heartworm in a dog with dirofilariasis (case report). Korean J Parasitol 2008, 46:171-173.

135. Megat Abd Rani PA, Irwin PJ, Gatne M, Coleman GT, Mclnnes LM, Traub RJ: A survey of canine filarial diseases of veterinary and public health significance in India. Parasites \& Vectors 2010, 3:30.

136. Hamilton JM, Weatherley A, Chapman AJ: Treatment of lungworm disease in the cat with fenbendazole. Vet Rec 1984, 114:40-41.

137. Grandi G, Calvi LE, Venco L, Paratici C, Genchi C, Memmi D, Kramer LH: Aelurostrongylus abstrusus (cat lungworm) infection in five cats from Italy. Vet Parasitol 2005, 134:177-182.

138. Schmid K, Duwel D: Use of fenbendazole (Panacur tablets ad us. vet.) against helminth infections in cats. Tierarztl Umsch 1990, 12:868-875.

139. Barrs VR, Swinney GR, Martin P, Nicoll RG: Concurrent Aelurostrongylus abstrusus infection and salmonellosis in a kitten. Aust Vet J 1999, 77:229-232.

140. Clayton HM: The management and treatment of respiratory nematode infections in small animals. Vet Ann 1983, 23:254-259.

141. Miller BH, Roudebush P, Ward HG: Pleural effusion as a sequel to aelurostrongylosis in a cat. J Am Vet Med Assoc 1984, 185:556-557.

142. Kirkpatrick CE, Megella C: Use of ivermectin in treatment of Aelurostrongylus abstrusus and Toxocara cati infection in a cat. J Am Vet Med Assoc 1987, 190:1309-1310.

143. Blagburn BL, Hendrix CM, Lindsay DS, Vaughan JL: Anthelmintic efficacy of ivermectin in naturally parasitized cats. Am J Vet Res 1987, 48:670-672.

144. Lewis DT, Merchant SR, Neer TM: Ivermectin toxicosis in a kitten. J Am Vet Med Assoc 1994, 205:584-586.

145. Traversa D, Di Cesare A, Milillo P, Lohr B, lorio R, Pampurini F, Schaper R, Paoletti $B$, Heine J: Efficacy and safety of imidacloprid 10\%/moxidectin $1 \%$ spot-on formulation in the treatment of feline aelurostrongylosis. Parasitol Res 2009, 105:55-62.

146. Traversa D, Milillo P, Di Cesare A, Lohr B, lorio R, Pampurini F, Schaper R, Bartolini $\mathrm{R}$, Heine J: Efficacy and safety of emodepside $2.1 \%$ /praziquantel $8.6 \%$ spot-on formulation in the treatment of feline aelurostrongylosis. Parasitol Res 2009, 105:83-89.

147. Willesen $\mathrm{J}$, Kristensen $A T$, Jensen AL, Heine J, Koch J: Efficacy and safety of imidacloprid/moxidectin spot-on solution and fenbendazole in the treatment of dogs naturally infected with Angiostrongylus vasorum (Baillet, 1866). Vet Parasitol 2007, 147:258-264.

148. Conboy G, Schenker R, Strehlau G: Efficacy of Milbemax (milbemycin/ praziquantel) for the treatment and prevention of Angiostrongylus vasorum infection in dogs. Proceedings of the Joint 49th Annual Meeting of the American Association of Veterinary Parasitologists/79th Meeting of the American Society of Parasitologists. 24-28 July 2004; Philadelphia 2006, 92.

149. Schnyder M, Fahrion A, Ossent P, Kohler L, Webster P, Heine J, Deplazes P. Larvicidal effect of imidacloprid/moxidectin spot-on solution in dogs experimentally inoculated with Angiostrongylus vasorum. Vet Parasitol 2009, 166:326-332

150. Conboy G, Hare J, Charles S, Settje T, Heine J: Efficacy of a single topical application of Advantage Multi (= Advocate) Topical Solution (10\% imidocloprid $+2.5 \%$ moxidectin) in the treatment of dogs experimentally infected with Crenosoma vulpis. Parasitol Res 2009 105:49-54.

151. Conboy G, Bourque A, Miller L, Seewald W, Schenker R: Efficacy of milbemycin oxime in the treatment of dogs experimentally infected 
with Crenosoma vulpis. Proceedings of the 52nd Annual Meeting of the American Association of Veterinary Parasitologists. Washington, DC 2007, 74.

152. Bihr T, Conboy GA: Lungworm (Crenosoma vulpis) infection in dogs on Prince Edward Island. Can Vet J 1999, 40:555-559.

153. Nelson CT, McCall JW, Rubin SB, Buzhardt LF, Doiron DW, Graham W, Longhofer SL, Guerrero J, Robertson-Plough C, Paul A: Guidelines for the diagnosis, prevention and management of heartworm (Dirofilaria immitis) infection in dogs. Vet Parasitol 2005, 133:255-266.

154. McCall JW, Guerrero J, Roberts RE, Supakorndej N, Mansour AE, Dzimianski MT, McCall SD: Further evidence of clinical prophylactic (reach-back) and adulticidal activity of monthly administration of ivermectin and pyrantel pamoate (Heartgard Plus) in dogs experimentally infected with heartworms. Proceedings of the "Recent Advances in Heartworm Disease, Symposium 2001" American Heartworm Society: 20-22 April 2001; Batavia, Illinois 2001, 189-200.

155. Rawlings CA, Bowman DD, Howerth EW, Stansfield DG, Legg W, Luempert LG III: Response of dogs treated with ivermectin or milbemycin starting at various intervals after Dirofilaria immitis infection. Vet Ther 2001, 2:193-207.

156. Venco L, McCall JW, Guerrero J, Genchi C: Efficacy of long-term monthly administration of ivermectin on the progress of naturally acquired heartworm infection in dogs. Vet Parasitol 2004, 124:259-268.

157. Atkins C, Miller MW: Is there a better way to administer heartworm adulticidal therapy? Vet Med 2003, 98:310-317.

158. Goodman DA: Evaluation of a single dose of melarsomine dihydrochloride for adulticidal activity against Dirofilaria immitis in cats. MS thesis University of Georgia, Athens, Georgia 1996, 95

159. McLeroy LW: Evaluation of melarsomine dihydrochloride for adulticidal activity against Dirofilaria immitis in cats with intravenously transplanted adult heartworms. MS thesis University of Georgia, Athens, Georgia 1998, 95.

160. Guerrero J, McCall JW, Genchi C: The use of macrocyclic lactones in the control and prevention of heartworm and other parasites in dogs and cats. "Macrocyclic Lactones in Antiparasitic Therapy" CABI Publishing, Oxon, UK 2002, 353-369.

161. Taylor MJ, Bandi C, Hoerauf A: Wolbachia bacterial endosymbionts of filarial nematodes. Adv Parasitol 2005, 60:245-284.

162. Kramer L, Grandi G, Leoni M, Passeri B, McCall J, Genchi C, Mortarino M, Bazzocchi C: Wolbachia and its influence on the pathology and immunology of Dirofilaria immitis infection. Vet Parasitol 2008, 158:191-195.

163. Bazzocchi C, Mortarino M, Grandi G, Kramer LH, Genchi C, Bandi C, Genchi M, Sacchi L, McCall JW: Combined ivermectin and doxycycline treatment has microfilaricidal and adulticidal activity against Dirofilaria immitis in experimentally infected dogs. Int J Parasitol 2008, 38:1401-1410.

164. Grandi G, Quintavalla C, Mavropoulou A, Genchi M, Gnudi G, Bertoni G, Kramer LH: A combination of doxycycline and ivermectin is adulticidal in dogs with naturally acquired heartworm disease (Dirofilaria immitis). Vet Parasitol 2010, 169:347-351.

165. McCall JW: The safety-net story about macrocyclic lactone heartworm preventatives: A review, an update and recommendations. Vet Parasitol 2005, 133:197-206.

166. Genchi C, Rossi L, Cardini G, Kramer LH, Venco L, Casiraghi M, Genchi M, Agostini A: Full season efficacy of moxidectin microsphere sustained release formulation for the prevention of heartworm (Dirofilaria immitis) infection in dogs. Vet Parasitol 2002, 110:85-91.

167. Lok JB, Knight DH, Nolan TJ, Grubbs ST, Cleale RM, Heaney K: Efficacy of an injectable, sustained release formulation of moxidectin in preventing experimental heartworm infection in mongrel dogs challenged 12 months after administration. Vet Parasitol 2005, 128:129-135.

168. Venco L, Mortarino M, Carro C, Genchi M, Pampurini F, Genchi C: Field efficacy and safety of a combination of moxidectin and imidacloprid for the prevention of feline heartworm (Dirofilaria immitis) infection. Vet Parasitol 2008, 154:67-70.

169. Caro-Vadillo A, Martínez-Merlo E, García-Real I, Fermín-Rodríguez ML, Mateo P: Verminous pneumonia due to Filaroides hirthi in a Scottish terrier in Spain. Vet Rec 2005, 157:586-589.

170. Torgerson PR, McCarthy G, Donnelly WJ: Filaroides hirthi verminous pneumonia in a West Highland white terrier bred in Ireland. J Small Anim Pract 1997, 38:217-219.
171. Juste RA, Garcia AL, Mencía L: Mixed infestation of a domestic cat by Aelurostrongylus abstrusus and Oslerus rostratus. Angew Parasitol 1992, 33:56-60.

doi:10.1186/1756-3305-3-62

Cite this article as: Traversa et al:: Canine and feline cardiopulmonary parasitic nematodes in Europe: emerging and underestimated. Parasites \& Vectors 2010 3:62.

\section{Submit your next manuscript to BioMed Central and take full advantage of:}

- Convenient online submission

- Thorough peer review

- No space constraints or color figure charges

- Immediate publication on acceptance

- Inclusion in PubMed, CAS, Scopus and Google Scholar

- Research which is freely available for redistribution

Submit your manuscript at www.biomedcentral.com/submit
Ciomed Central 